University of Louisville

ThinkIR: The University of Louisville's Institutional Repository

Electronic Theses and Dissertations

$11-2011$

\title{
A variable duty cycle maximum power point tracking algorithm for wind energy conversion systems.
}

George Joseph 1988-

University of Louisville

Follow this and additional works at: https://ir.library.louisville.edu/etd

\section{Recommended Citation}

Joseph, George 1988-, "A variable duty cycle maximum power point tracking algorithm for wind energy conversion systems." (2011). Electronic Theses and Dissertations. Paper 716.

https://doi.org/10.18297/etd/716

This Master's Thesis is brought to you for free and open access by ThinkIR: The University of Louisville's Institutional Repository. It has been accepted for inclusion in Electronic Theses and Dissertations by an authorized administrator of ThinkIR: The University of Louisville's Institutional Repository. This title appears here courtesy of the author, who has retained all other copyrights. For more information, please contact thinkir@louisville.edu. 


\title{
A VARIABLE DUTY CYCLE MAXIMUM POWER POINT TRACKING ALGORITHM FOR WIND ENERGY CONVERSION SYSTEMS
}

\author{
By \\ George Joseph \\ B-Tech, University of Calicut, 2010 \\ A Thesis \\ Submitted to the Faculty of the \\ J.B. Speed School of Engineering \\ in Partial fulfillment of the requirements \\ for the Degree of
}

Master of Science

Electrical and Computer Engineer Department

University of Louisville

Louisville, Kentucky

December 2011 


\section{A VARIABLE DUTY CYCLE MAXIMUM POWER POINT TRACKING ALGORITHM FOR WIND ENERGY CONVERSION SYSTEMS}

By

George Joseph

B-Tech, University of Calicut, 2010

A Thesis Approved on

November 5, 2011

By the following Thesis Committee:

Dv. Chris Forexan

\begin{tabular}{l} 
Thesis Xdvisor \\
DA.Y.hohn Naber \\
Thesis Co-Advisor Michael McIntyre \\
\hline
\end{tabular}

Dr. Adel Elmaghraby 


\section{DEDICATION}

This thesis is dedicated to my family members

Mr. K T Joseph

Mrs. Annie Joseph

Mr. Thomas Joseph

Mrs. Misha Joseph

And

Mr. Anup Paul

Who have been constant sources of inspiration to me. 


\section{ACKNOWLEDGMENTS}

I would like to express my sincere gratitude to Dr. Chris Foreman who has guided me from the inception of the thesis. I would like to thank Dr. John F Naber who has served as my Co-Advisor. I would also like to extend my heartfelt gratitude to Dr. Michael McIntyre and Dr. Adel S Elmaghraby for their valuable suggestions to make this thesis more fruitful and effective. I would also like to remember all my family members for supporting me throughout my studies. 


\begin{abstract}
A VARIABLE DUTY CYCLE MAXIMUM POWER POINT TRACKINGALGORITHM FOR WIND ENERGY CONVERSION SYSTEMS
\end{abstract}

George Joseph

November 5, 2011

This thesis proposes a new Maximum Power Point Tracking (MPPT) algorithm employed in Wind Energy Conversion Systems (WECS). One of the major issues discussed in the literature concerning HCS is its inefficiency in detecting the peak power when there is a change in wind speed. In addition, the HCS produces oscillations in delivered power once this peak is detected. A modified HCS algorithm is proposed in this thesis to overcome these limitations. This algorithm employs a variable duty cycle to reduce the oscillations in delivered power once the peak power is detected. The performance of the proposed algorithm was evaluated using MATLAB-SIMULINK. Efficiencies of $95.48 \%, 98.8 \%$, and $92.2 \%$ were observed under constant wind speed, abrupt wind speed change from $10 \mathrm{~m} / \mathrm{s}$ to $5 \mathrm{~m} / \mathrm{s}$, and a continuously varying wind speed between $5 \mathrm{~m} / \mathrm{s}$ and $12 \mathrm{~m} / \mathrm{s}$ respectively. The traditional HCS algorithm was also simulated for comparison with efficiencies reduced to $76.27 \%, 81.35$, and $67.86 \%$ under the same conditions. These efficiency improvements and the reduction of oscillations during varying wind speeds demonstrate the major achievements of the proposed algorithm. 
TABLE OF CONTENTS

PAGE NO.

ACKNOWLEDGMENT

iv

ABSTRACT

$\mathbf{v}$

LIST OF FIGURES

$\mathbf{x}$

1 INTRODUCTION 1

1.1 CONCEPT OF MAXIMUM POWER POINT TRACKING ALGORITHMS 2

1.2 ORGANIZATION OF THESIS $\quad$ - 4

2 WIND ENERGY CONVERSION - PRINCIPLES AND SYSTEMS 6

2.1 WIND ENERGY CONVERSION PRINCIPLES 6

2.2 WIND ENERGY CONVERSION SYSTEMS (WECS) 10

2.3 COMPONENTS OF WIND ENERGY CONVERSION SYSTEMS 13

$\begin{array}{lll}\text { 2.3.1 Wind Turbines } & 13\end{array}$

$\begin{array}{lll}\text { 2.3.1.1 Parts of a Wind Turbine } & 15\end{array}$

$\begin{array}{lll}2.3 .1 .1 .1 & \text { Rotor } & 16\end{array}$ 


\section{TRADITIONAL MAXIMUM POWER POINT TRACKING ALGORITHMS 21}

3.1 CONVENTIONAL WECS MPPT ALGORITHMS 
5.1 PROPOSED ALGORITHM

5.3 MATHEMATICAL MODELING OF WIND ENERGY CONVERSION SYSTEMS

5.3.1 Wind Turbine

5.3.2 Permanent Magnet Synchronous Generator (PMSG) 
6.2 SUGGESTED IMPROVEMENTS 


\section{LIST OF FIGURES}

1. Wind Turbine Power Curves 03

2. Variation of Turbine Power with Rotational Velocity at a Given Wind Speed 09

3. Variation of $C_{p}$ with TSR 09

4. $C_{p}$-TSR Curve (DIY energy projects) 10

5. Fixed-speed WECS Configuration (Energetic Drives) 11

6. Doubly Fed WECS 12

7. Components of WECS (scielo) 13

8. Vertical Axis Wind Turbine (Green Energy 2011) 14

9. Horizontal Axis Wind Turbine (Powered by mother nature) 15

10. Parts of a Wind Turbine (National Instruments) 15

$\begin{array}{ll}\text { 11. Three Phase Bridge Rectifier (reuk.com) } & 18\end{array}$

12. Boost Converter-Current Flow Diagram (Coilgun Systems) 19

13. Block Diagram Representation of HCS Method 22

14. PSF Method Block Diagram (Adegas, Alé, Reis, Simioni, \& Tonkoski, 2006) 24

15. Oscillations in Peak Power Using Traditional HCS Method (Tafticht, Agbossou,

$\begin{array}{ll}\& \text { Cheriti, 2006) } & 29\end{array}$ 
16. Effect of Smaller Step Size on MPPT 30

17. Effect of Larger Duty Cycle on Power Point Tracking 30

18. Proposed Algorithm Flow Chart 35

19. Operating Point Just Beyond the Peak 37

20. Operating Point Far Beyond Peak Power 38

21. Characteristics of the Simulated Wind Turbine 40

22. Constant Wind Speed Profile $(5 \mathrm{~m} / \mathrm{s})$

23. Output Power - Constant Wind Profile 46

24. DC Link voltage - Constant Wind Profile 47

25. Regulated DC Voltage - Constant Wind Profile 47

26. Simulated Wind Profile - Abrupt Wind Speed Change 48

27. Turbine Power - Comparison during Abrupt Wind Speed Change 48

28. Regulated Output Voltage during Abrupt Wind Speed Change 49

29. Varying Speed Wind Profile 50

30. Power Produced during Randomly Varying Wind Conditions 51

31. Regulated Output Voltage - Randomly Varying Wind Conditions 51

32. Variation of Duty Cycle (D) to Aid the MPPT 52 


\section{CHAPTER 1}

\section{INTRODUCTION}

The dependence on non-renewable energy sources like coal, natural gas and nuclear energy has reached such an extent that these resources have shown signs of depletion (www.renewable-energy-sources.com). This has led to a global increase in the prices of the energy harnessed from these sources (Congress of the United States Congressional Budget Office, 2006). In addition to the economic impacts, this dependence on non-renewable resources has caused serious environmental issues. For example, a single $100 \mathrm{MW}$ coal power plant produces approximately 25 pounds of mercury (A Greenpeace Southeast Asia Report, 2005), which can spread approximately 600 miles from the source (Greenpeace Briefing). Some of the other issues associated with utilizing these non-renewable resources are that they present a serious threat to wildlife during the various stages of harnessing the energy and the disposal of associated wastes. These concerns have encouraged research and development of renewable resources like solar, wind, hydro, tidal, and geothermal energy. These renewable energy sources are also very eco-friendly, with fewer emissions and issues related to waste disposal. 
As renewable sources do not require mining and transportation, they do not threaten wild life. In addition to these direct advantages, there are many hidden economic advantages to adopting renewable energy. These include: revitalization of rural communities by making use of otherwise wasted lands; reduction in transportation costs as the fuel is available at the place of production; and stabilization of price among others.

Even though renewable energy is a good substitute for conventional sources, there is some skepticism associated with their performance and cost. Engineers have been working to address these concerns. A unique limitation of energy conversion systems such as wind and solar is their inability to track peak power production efficiently at varying wind speeds and solar insolation respectively. This has led to control algorithms referred to as MPPT algorithms. These aid wind and solar energy conversion systems in extracting the maximum available power for a given wind and solar resource. This thesis analyzes conventional methods of MPPT in wind conversion systems, including the popular Hill Climb Search (HCS) method. After demonstrating the limitations associated with this legacy method, a new adaptive control algorithm for MPPT is proposed.

\subsection{CONCEPTS OF MAXIMUM POWER POINT TRACKING ALGORITHMS}

The algorithms involved in harvesting the maximum possible power from a conversion system such as wind or solar, are known as MPPT algorithms. This section investigates MPPT techniques applied to wind energy conversion systems.

Wind turbines can have two types of blade angle pitch. They can be either fixedpitch or variable-pitch type blades. In variable-pitch turbines, MPPT is achieved by controlling the pitch angle of the turbine blades. Here pitch actuators are controlled to move the pitch of turbine so that the aerodynamic power extracted by the wind turbine 
and subsequently the electric power at the generator output is matched to the load for maximum power transfer (Muljadi \& Butterfield, 2001). This thesis simulated wind turbines of the second type, referred to as fixed-pitch wind turbines. In these turbines, maximum power is extracted by application of a power converter stage and an associated MPPT algorithm to control the operation of the converter. Based on the axis of the rotation of blades, wind turbines may be classified as horizontal or vertical axis wind turbines. These have been explained in detail in Section 2.3.

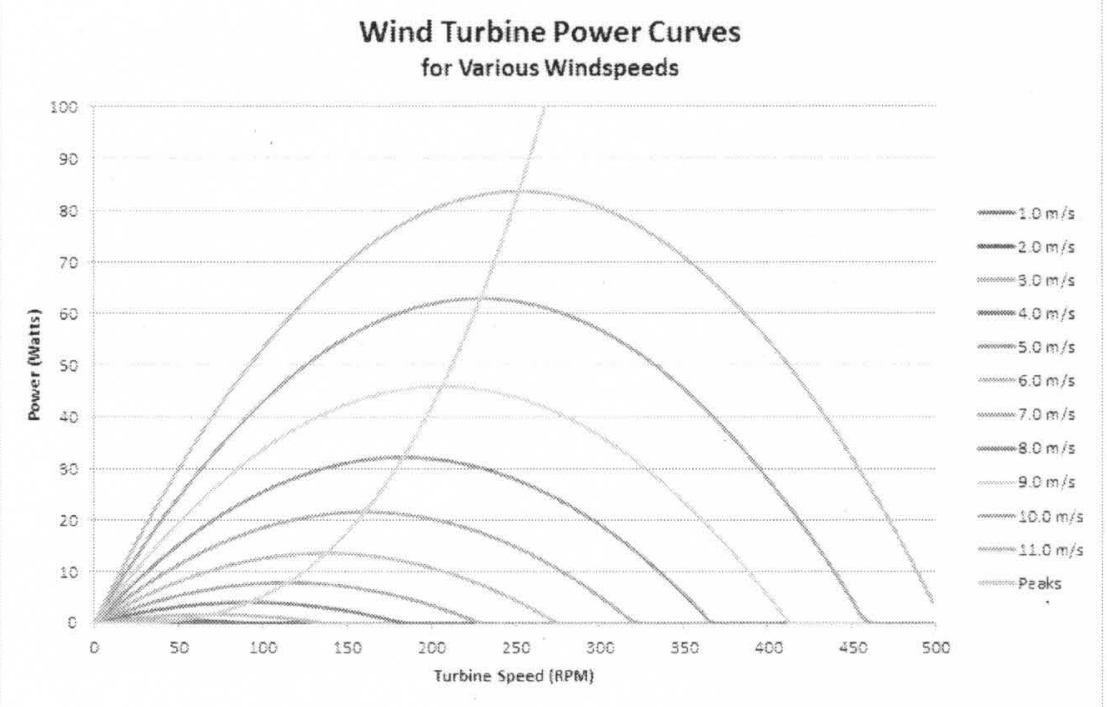

Figure 1. Wind Turbine Power Curves (Caleb Engineering, LLC)

Figure 1 shows the variation in the power produced by a typical wind turbine at different wind velocities. This graph is often called the wind turbine characteristic graph, or simply the power curve of the wind turbine. From Figure 1, it can be seen that for a particular wind speed, there exists a maximum power that can be produced by a turbine, 
which is produced when the turbine is operated at the optimal rotor speed. Recalling Figure 1, the increasing orange line connects all such peak power points of the turbine. An ideal MPPT algorithm always aims to operate the turbine at the intersections along this line with the power curves. The rotor speed is highly dependent on both the wind speed and the generator loading. Most MPPT algorithms tend to optimize the generator loading so that the optimum rotor speed is maintained (Amei, Takayasu, Ohji, \& Sakui). This is done by changing the output impedance seen at the generator output using a switching converter. A MPPT algorithm essentially provides the intelligence that directs the switching of these converters.

\subsection{ORGANIZATION OF THE THESIS}

Organization of the thesis is as follows:

Chapter 1 provides an outline of the requirement for research in renewable energy, including the unique limitations that the associated energy conversion systems present. An introduction to the concept of MPPT is also provided. Chapter 2 describes the basic theories and principles behind Wind Energy Conversion Systems (WECS), including a study of the individual components. This section provides comprehensive information on WECS prior to the description of MPPT algorithms in Chapter 3. Chapter 3 explores some common methods of MPPT, including HCS, in detail as applied to solar and wind energy conversion systems. Chapter 4 defines the thesis problem and also reviews the major research efforts completed by others in the area of MPPT as applied to solar and wind energy conversion systems. Chapter 5 introduces the novel adaptive MPPT algorithm proposed, which addresses the thesis problem defined in Chapter 4 and limitations discussed in the Abstract. A brief description of the simulation environment 
and the mathematical models of the WECS are also provided. Simulation results of the effectiveness of the proposed algorithm are included for verification. Chapter 6 discusses these achievements of the proposed algorithm with suggestions for improvement as well as future directions for research in this field. 


\section{CHAPTER 2}

\section{WIND ENERGY CONVERSION - PRINCIPLES AND SYSTEMS}

This chapter introduces basic principles involved in the conversion of wind energy to electrical energy and the various components forming a Wind Energy Conversion Systems (WECS) to aid this conversion. A comprehensive introduction to these principles and the role of the various components of a WECS are required to understand how MPPT algorithms function.

\subsection{WIND ENERGY CONVERSION PRINCIPLES}

Being a moving quantity, wind possesses kinetic energy. This energy is given by classical physics as in Equation (2.1).

$$
\begin{aligned}
& E_{\text {kinetic }}=(1 / 2) m v_{\mathrm{wd}}{ }^{2} \\
& E_{\text {kinetic }}=(1 / 2) A \cdot \rho \cdot d \cdot v_{\mathrm{wd}}{ }^{2}
\end{aligned}
$$

Where, $E_{\text {kinetic }}$ is kinetic Energy, $\mathrm{m}$ is mass of air, $\rho$ is the density of air, $\mathrm{d}=$ diameter, $v_{\mathrm{wd}}=$ velocity of wind, $\mathrm{A}=$ area swept by rotor. Equation 2.2 gives the theoretical total energy associated with the wind blowing across a wind turbine. The mass of fluid that crosses the wind turbine each second is given by its mass flow rate $\dot{m}$. 
$\dot{m}$ is related to air density, turbine area $A$, and wind velocity $v_{\text {wd }}$ by the following equation:

$$
\dot{m}=A \cdot \rho \cdot v_{\mathrm{wd}}
$$

Where $v_{\text {wd }}$ can be considered to be the average value of the wind velocities in front of the rotor and behind the rotor, which is represented as $v_{1}$ and $v_{2}$.

This average value can be found by the equation...

$$
v_{\mathrm{wd}=} \frac{1}{2}\left(v_{1}+v_{2}\right)
$$

The force produced is given by $F=m \cdot a$ where $a$ is the acceleration.

$$
\mathrm{F}=\mathrm{m} \frac{d \mathrm{v}_{\mathrm{ud}}}{d t}
$$

The power produced by the turbine, $P$ is given as...

$$
\begin{aligned}
& \mathrm{P}=\frac{d \mathrm{E}_{\text {knutic }}}{d t}=\dot{E} \\
& =\frac{1}{2} \dot{m} \cdot\left(v_{1}{ }^{2}-v_{2}{ }^{2}\right)
\end{aligned}
$$

Substituting the value of $\dot{m}$ from Equation (2.3) in (2.7)...

$$
\mathrm{P}=\frac{1}{2} \rho \cdot A \cdot\left(v_{1}^{2}-v_{2}^{2}\right) \cdot v_{\mathrm{wd}}
$$

Substituting for $v_{\mathrm{wd}}$ from Equation 2.4,

$$
\begin{aligned}
& \dot{E}=\frac{1}{4} \rho \cdot A \cdot\left(v_{1}{ }^{2}-v_{2}{ }^{2}\right) \cdot\left(v_{1}+v_{2}\right) \\
& =\frac{1}{4} \rho \cdot A \cdot v_{1}^{3} \cdot\left(1-\left(\frac{v_{2}}{v_{1}}\right)^{2}+\left(\frac{v_{2}}{v_{1}}\right)-\left(\frac{v_{2}}{v_{1}}\right)^{3}\right)
\end{aligned}
$$


By differentiating $\dot{E}$ with respect to $\frac{v_{2}}{v_{1}}$, we find the maximal point occurs when $\frac{v_{2}}{v_{1}}=\frac{1}{3}$. Substituting this value, the maximum power...

$$
\mathrm{P}_{\max }=\frac{16}{27} \cdot \frac{1}{2} \cdot \rho \cdot A \cdot v_{1}{ }^{3}
$$

The value of $\frac{16}{27}=0.593$ is known as Power Coefficient $\left(C_{p}\right)$.

The above being formulated by the German scientist, Albert Betz (Betz, 1966), the value 0.593 is called the Betz limit. $C_{p}$ is defined as the ratio of power output from the wind turbine and the total wind energy available in the wind. This essentially means that the maximum possible efficiency by a wind turbine is $59.3 \%$. The value of $C_{p}$ is dependent on the Tip Speed Ratio (TSR) and pitch angle of the turbine with the longitudinal axis. TSR is defined as ratio of the rotational speed of the tip of the blade to the wind speed as stated in Equation (2.3).

$$
T S R=R \cdot \omega / v_{\mathrm{wd}}
$$

Where $\omega=$ rotational speed of the tip of the turbine blade, $R=$ radius of the wind turbine. So taking turbine efficiency into consideration, Equation (2.2) can be restated as:

$$
E_{\text {kinetic }}=(1 / 2) \cdot C_{p}(\mathrm{TSR}, \beta) \cdot A \cdot \rho \cdot d \cdot v_{\mathrm{wd}}
$$

Where $C_{p}=$ Power Coefficient, TSR $=$ Tip speed ratio, $\beta=$ pitch angle of the turbine. 


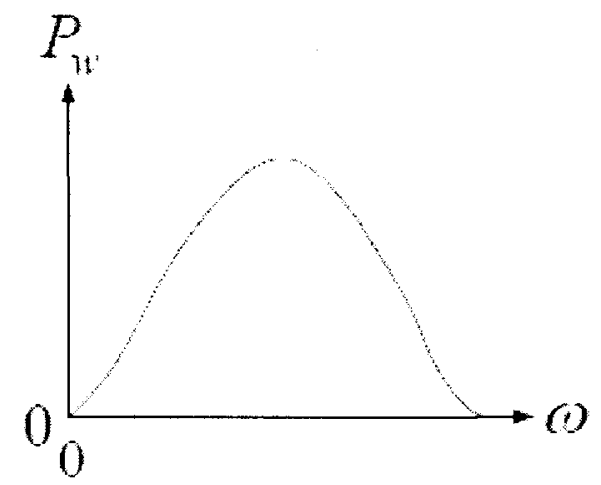

Figure 2. Variation of turbine power with rotational velocity at a given wind speed

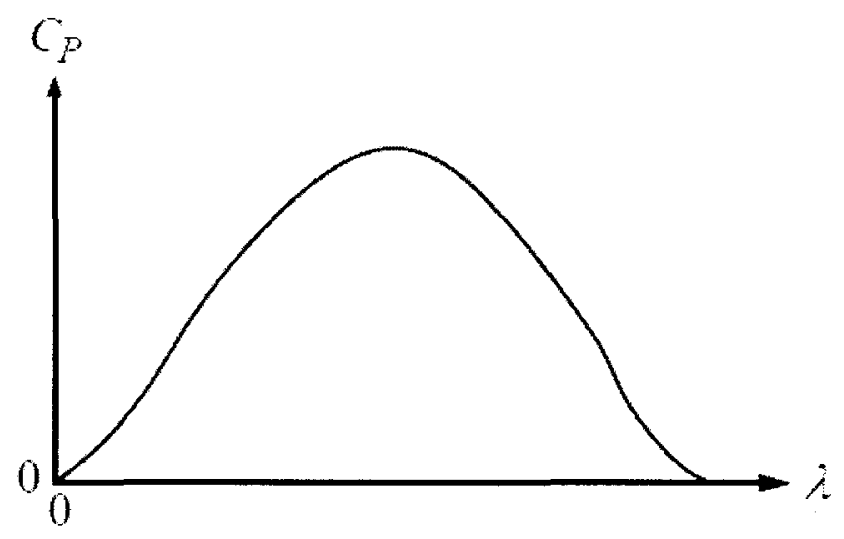

Figure 3. Variation of $C_{p}$ with TSR

Shown in Figure 2 is the variation of turbine power with the rotational speed. A MPPT algorithm aims at extracting the power corresponding to the peak of this curve by operating at the corresponding rotational speed. Figure 3 shows the variation of $C_{p}$ with TSR. The peak point of the graph corresponds to the optimal value of $C_{p}$. 


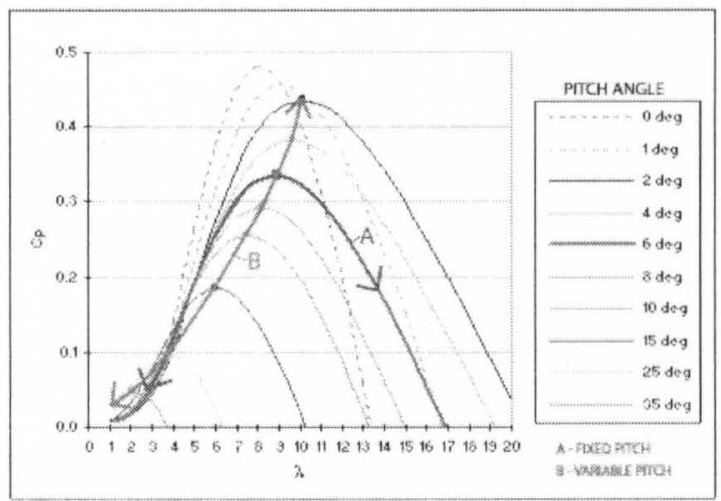

Figure 4. $C_{p}$-TSR Curve ( DIY energy projects)

The graph shown in Figure 4 is a typical graph of $C_{p}$ versus TSR value at different pitch angles for a wind turbine. This graph is also called the wind turbine performance graph. It can be seen that $C_{p}$ has its maximum value at one particular value of TSR for a given blade pitch. Hence by being able to maintain the TSR to this optimum value, the maximum value of $C_{p}$ can be maintained consistently, and thereby extract the maximum power from the turbine. The power coefficient curve is normally given by the turbine manufacturer or determined through field testing.

Recalling Figure 1, maximum power is obtained at a particular optimum rotational speed of the turbine for a given wind speed. This rotational speed also corresponds to the speed the turbine has to rotate for achieving optimal TSR. The MPPT regulates the rotational speed so that it stays at its optimal value corresponding to the maximum power point.

\subsection{WIND ENERGY CONVERSION SYSTEMS (WECS)}

Based on the speed of rotation, WECS can be fixed-speed systems or variablespeed systems. Fixed-speed systems are usually used with doubly fed induction 
generators or squirrel cage induction generators because induction generators are a low cost solution for constant speed systems. In fixed-speed systems, the turbine is normally connected directly to the grid as opposed to the use of a power electronic based speed control circuit. Such circuits would use power electronic circuits to vary the generator rotational speed. Figure 5 shows a fixed-speed wind energy conversion system, which uses a squirrel cage induction generator. A gear box is used to transfer the rotation from the wind turbine to the induction generator shaft. Since the induction generator can be made to operate with very narrow speed variations, the system can be considered to be a constant speed one (Qaio, Harley, \& Venayegamoorthy, 2007) with the generator operating at grid frequency.

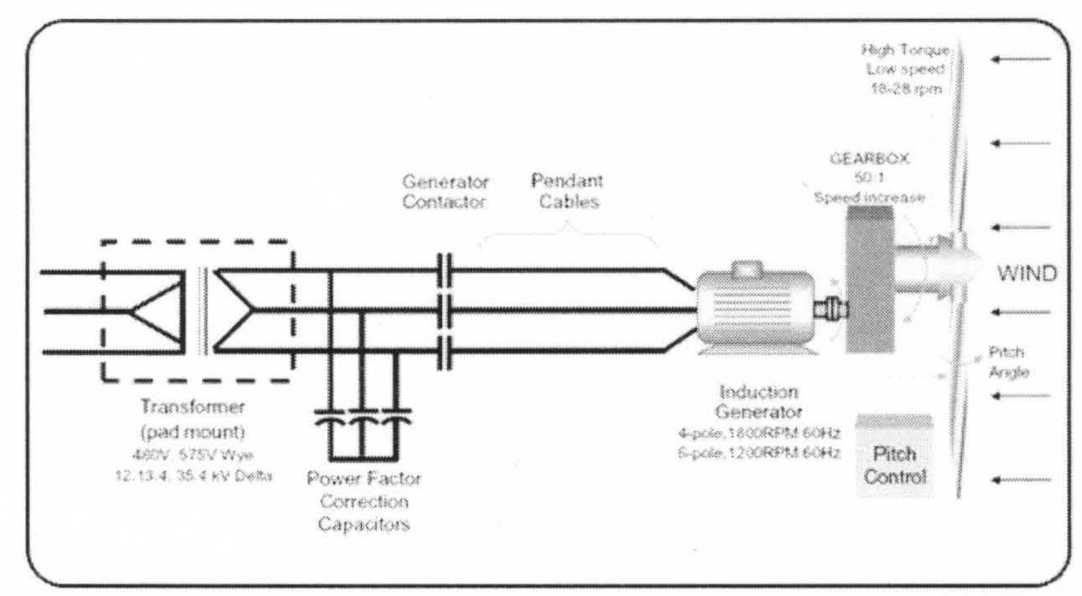

Figure 5. Fixed-speed WECS configuration (Energetic Drives)

Fixed-speed conversion systems are advantageous in the fact that they are much cheaper and have less revolving parts (Serban, Ion, \& Marinescu, 2008). However, the advantage of variable-speed systems is that maximum power point tracking is easily incorporated in the power converter stage (Serban, Ion, \& Marinescu, 2008). 
Variable-speed systems have a varying rotational speed and often they have a power electronic converter stage between the turbine and grid. This can be controlled by MPPT algorithms for better efficiency. The proposed algorithm addresses MPPT control for variable-speed wind energy conversion systems. A very popular form of variablespeed systems is the doubly fed systems using doubly fed induction generators. This has been depicted in Figure 6.

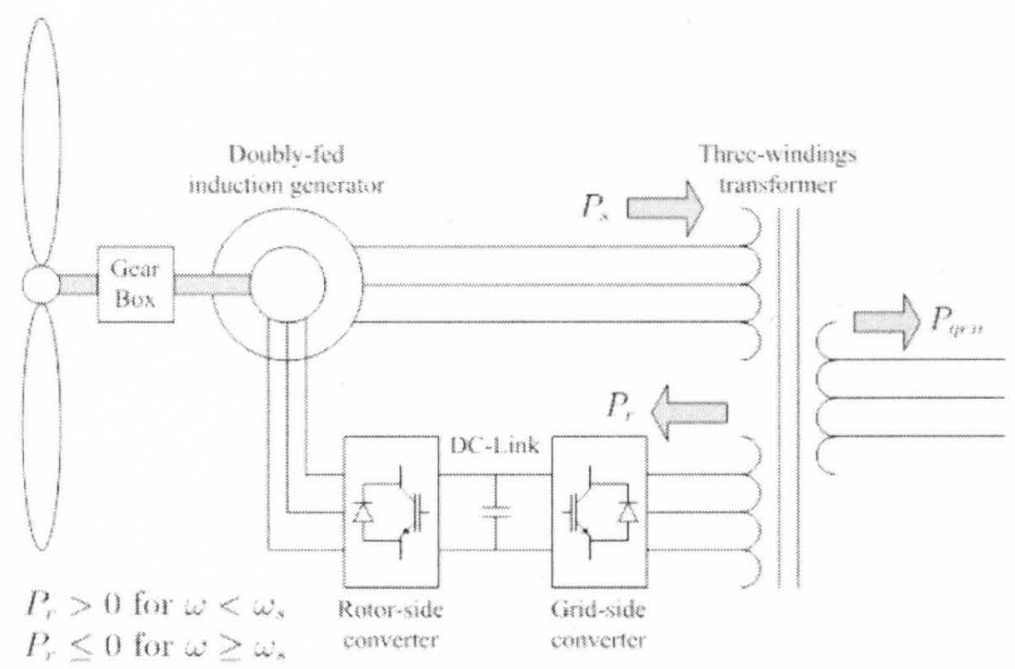

Figure 6. Doubly Fed WECS.

A doubly fed induction generator has windings both on stator and rotor. When used for wind energy conversion systems, the stator of this generator is connected directly to the grid while the rotor is connected to converters. The grid side converter shown in Figure 6 is normally controlled to achieve a unity power factor. The advantage of this system is its lower cost, ease in power factor correction and also variable-speed operation is achieved. 


\subsection{COMPONENTS OF WIND ENERGY CONVERSION SYSTEMS}

This section outlines the major components that make up a complete wind energy conversion system. Figure 7 shows the block diagram of a wind energy conversion

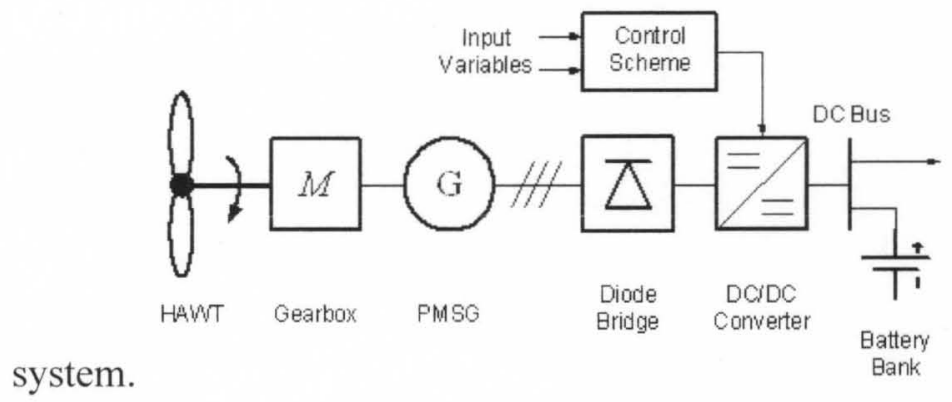

Figure 7. Components of WECS (scielo)

Figure 9 depicts a horizontal axis wind turbine. This turbine is coupled to a permanent magnet synchronous generator, which converts the mechanical energy produced by the rotating blades to the electrical equivalent. This AC voltage produced at the generator terminal is then converted to a DC voltage of the required voltage level to charge the battery systems. However, as this thesis was aimed to prove the efficacy of a new algorithm, battery dynamics were not simulated. In practical systems, this battery stage, if utilized, is often integrated with an inverter stage so that the system can supply power to the AC grid. A detailed description of the various components of a WECS has been given later in this chapter.

\subsubsection{Wind Turbines}

Wind turbines form the front end of a WECS. It provides the necessary torque by harvesting energy in the wind to rotate the generator shaft. Wind turbines can be classified as Horizontal Axis Wind Turbines (HAWTs) or Vertical Axis Wind Turbines (VAWTs) based on the axis of rotation of the blades. 


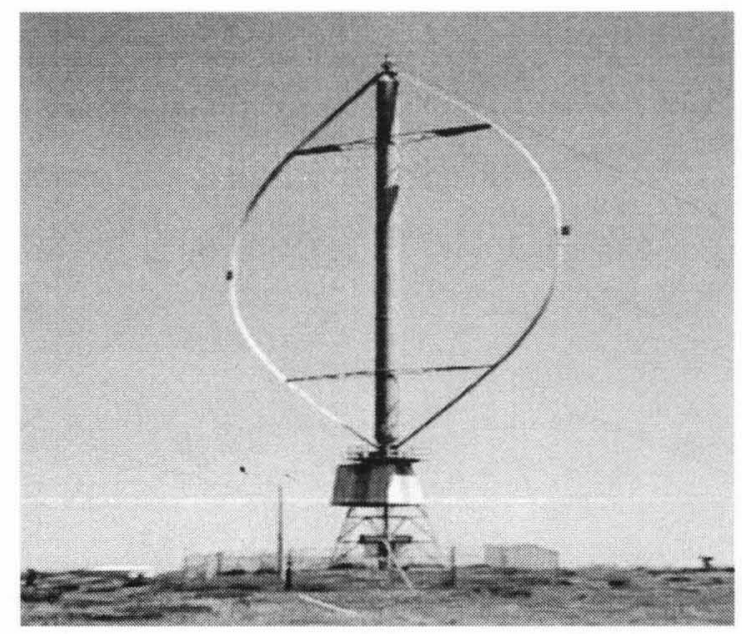

Figure 8. Vertical Axis Wind Turbine (Green Energy 2011)

As seen in Figure 8, a VAWT rotates around a vertical axis. The advantage of using such a system is that they can start to generate power at a much lower wind speed than HAWTs and for this reason, they can be mounted at lower elevations (Dang, 2010). This makes it suitable for residential applications (Dang, 2010). Also, VAWTs are quieter and more aesthetic (Dang, 2010). These can be used in applications where power is required just for the local load, as opposed to supplying the utility grid. However, VAWTs present limitations related to efficiency and power production compared to HAWTs and therefore cannot be used for commercial applications. The reduced power production is due to the fact that its blades experience more drag (Dang, 2010). Another limitation they present is the use of guide wires which cause downward thrust to the turbine bearings and thereby increasing bearing wear.

A HAWT can be pitch controlled, which makes it very useful. However, a disadvantage of using HAWT is that these require higher winds to operate and hence have to be mounted on a tall structure, which adds to their cost. This work focuses on 
HAWT for MPPT development and simulation results prove the efficacy of the proposed MPPT algorithm.

Shown in Figure 9 is a HAWT system. It can be seen that the turbine blades are placed in such a manner that the turbine rotates along the horizontal axis unlike the vertical axis counter parts.

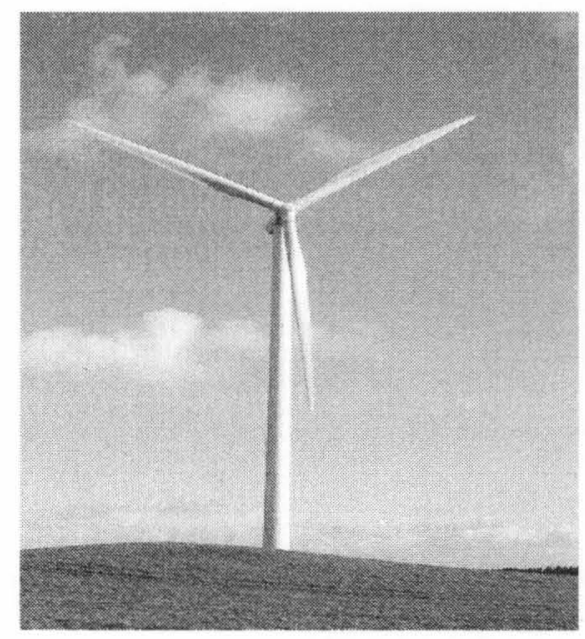

Figure 9. Horizontal Axis Wind Turbine (Powered by mother nature)

\subsubsection{Parts of a Wind Turbine}

Shown in Figure 10 are the various parts of a wind turbine. Major parts of a wind turbine are its rotor and gearbox, which leads to the generator section.

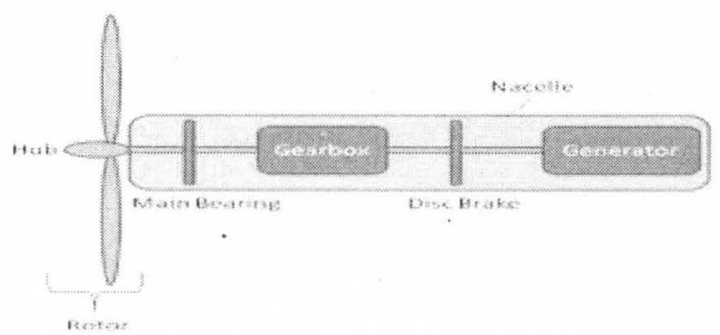

Figure 10. Parts of a Wind Turbine (National Instruments) 
Given in the following sections is a detailed description of the various parts of a wind turbine.

\subsection{Rotor}

The turbine rotor is the rotating part of a wind turbine, which essentially converts wind velocity to rotational torque, which in turn rotates the generator rotor.

\subsection{Braking System}

Braking systems are used to make sure that the wind turbine shuts down once the maximum tolerable wind speed limit has reached to ensure safety. There are two basic braking systems namely active stall control and passive stall control. Active stall control makes use of sensors to measure wind speed and then alters the pitch of the wind turbine accordingly so that the amount of wind captured by the wind turbine blade is reduced. In passive stall method, mechanical design is such that they induce turbulence at a set wind speed, causing stall (Dang, 2010).

\subsection{Shaft and gear box}

The shaft is connected to the center of the rotor and rotates as the rotor rotates. Rotations of the shaft are coupled to a gearbox to multiply the rotational speed supplied to generator. The rotational speed of the turbine is multiplied by the gear ratio $(\mathrm{N})$ such that the generator has a proportionally increased or reduced rotational speed.

\subsubsection{Generator}

The generator converts the rotational torque supplied by the wind turbine rotor to an equivalent electrical power. Any electrical generator works on the principle of electromagnetic induction, i.e., a rotation of the magnetic generator rotor induces an EMF 
in the stator coils causing current to be produced. The two types of generators that are used most often with WECS are the induction generator and synchronous generator.

The magnet used in the rotor can be a permanent magnet or an electromagnet using a DC current input. The former generator is called as Permanent magnet synchronous generator (PMSG). The subsequently presented simulation results verify the algorithm using the PMSG.

The other type of generator often used with WECS is an induction generator, which operates above synchronous speed.

\subsubsection{Rectifier}

Rectifiers are used to convert the $\mathrm{AC}$ voltage produced by the generator into an equivalent DC voltage. A capacitor is used as a voltage filter. Rectifier circuits are made of switches made from diodes, IGBTs or thyristors. The rectifier circuits that employ diodes are called uncontrolled rectifiers. A rectifier can be either half-wave or full-wave. Half-wave rectifiers are those that rectify either the positive or negative half cycle of an $\mathrm{AC}$ input cycle. The full wave rectifier passes the positive cycle of an $\mathrm{AC}$ input wave during all of its time period.

The simulated WECS used a three phase diode rectifier to convert the AC voltage produced by a generator to a DC voltage. Figure 11 shows a three phase diode rectifier. It has two sets of diodes. A set of diodes connected to the positive DC output and another set of diodes connected to the negative terminal of the DC output. The former set of diodes are turned on during the positive half cycle, while during the second half cycle the later set of diodes operate to give a positive output during both cycles. 


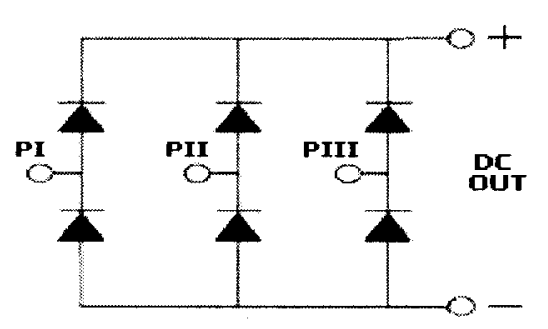

Figure 11. Three Phase Bridge Rectifier (reuk.com)

Design of an uncontrolled Bridge rectifier involves the selection of diodes with the right blocking voltage. Blocking voltage refers to the maximum reverse voltage the diodes constituting the rectifier can with stand. Also, they must be sized to withstand the maximum conduction current even when there is a surge. The conduction current refers to the current that passes through the diode as it is being forward biased. Another point to be noted is that in all the cases of rectifiers explained above, a smoothening filter is required to obtain a smooth $\mathrm{DC}$ output along with a heat sink for the thermal management.

\subsubsection{DC-DC Converters}

DC-DC converters are used to obtain a regulated output voltage from a given input voltage. In WECS, this power electronic converter stage is used after the rectifier stage to provide a regulated DC output voltage for load like battery. DC to DC converters are essentially circuits involving IGBT or MOSFET based switches to obtain a regulated output voltage level. MOSFET switches are used where a fast switching frequency is required. IGBT is selected where there is a need for high voltage tolerance. Three common DC-DC converters are Buck converters or Step Down converters, Boost converters or step up converters and Buck-Boost converters, which can step up or down a given input voltage. DC-DC converters are often called as switchers, switching power 
supplies, switched mode converters or DC choppers. The switching takes place at a high frequency to produce a pulse waveform of required time period. As there is no power absorbed by an ideal switch, the thesis assumes that the net power given out by the rectifier is available at the load end at the output of the DC-DC converter.

Buck converters or step down converters are used when the input voltage is higher than the desired output voltage. Boost converters are used in situations where there is a need for the output voltage to be higher than the input voltage. Buck-Boost converters are converters that can perform both boosting and step down operations. The thesis simulated a boost converter to obtain a regulated output voltage.

\subsubsection{Boost Converters}

Boost converters are used to switch a voltage at lower level to higher level at the same power and hence they are also called step up converter. Figure 11 shows the implementation of a boost converter circuit.
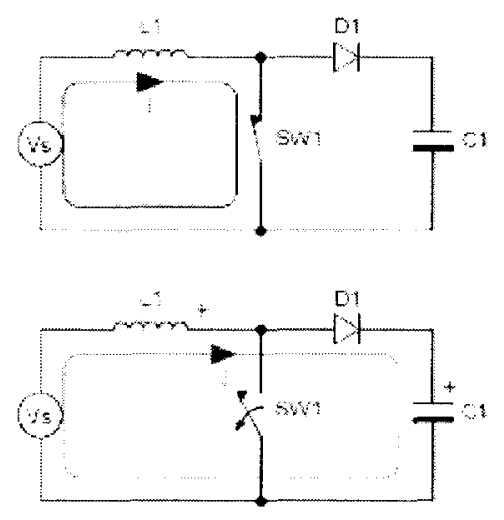

Figure 12. Boost Converter Current Flow Diagram (Coilgun Systems)

During the time for which the switch is closed, the inductor charges and the associated circuit is as depicted in Figure 12. During the time when the switch is 
open, the developed voltage is pushed to the load through the diode and capacitor.

The average value or the $\mathrm{DC}$ value of the pulse produced is given by:

$$
V_{o}=V_{s} /(1-D)
$$

Where $V_{o}$ refers to the DC component of the output voltage, $V_{s}$ is the source voltage and

$\mathrm{D}$ is the duty cycle of switching. Duty cycle is defined as $T_{o n} /\left(T_{o n}+T_{o f f}\right)$ where $T_{o n}$ is the ON time of the converter while $T_{\text {of }}$ is the OFF time. 


\section{CHAPTER 3}

\section{TRADITIONAL MAXIMUM POWER POINT TRACKING ALGORITHMS}

In Chapter 2, the various physical parts of a Wind Energy Conversion Systems WECS were been examined. The next step is to develop an understanding of the traditional MPPT algorithms adopted in wind energy conversion systems (WECS). These methods are discussed briefly in this chapter. Recall from Chapter 2 that DC-DC converters are switched with specific duty cycle ratios to regulate the output voltage. As stated earlier, MPPT algorithms provide the necessary intelligence required to switch the power converters so as to maximize the power extracted from wind mill. This is because given a fixed-output voltage for the converter, changing its duty cycle results in changing the output voltage across the generator terminals. This indicates the generator output impedance is changed, which regulates the rotational speed of the generator and wind turbine. The following section describes the various conventional methods of MPPT in both WECS.

\subsection{CONVENTIONAL WECS MPPT ALGORITHMS}

Following sections give a brief idea of the various WECS MPPT algorithms. A description of the conventional methods of Hill Climb Search (HCS), Tip Speed Ratio 
(TSR), and Power Signal Feedback (PSF) is discussed. Following this is a brief description of the various studies conducted in the field.

\subsubsection{Hill Climb Search (HCS) method}

HCS method of MPPT makes use of the inverted U shaped graph between power and rotor speed illustrated in Figure 2. As there is a definite peak power corresponding to a particular rotor speed, the algorithm compares the present power at an instant to the power obtained at the previous step. If the power is found to be increasing, then the duty cycle of the gating pulse applied to the converter switches are increased to drive the operating point more towards the peak power. If the power is found to be decreasing, then the duty cycle is reduced. Figure 13 shows the flow chart of the algorithm of HCS method (Xiao \& Dunford, 2004).

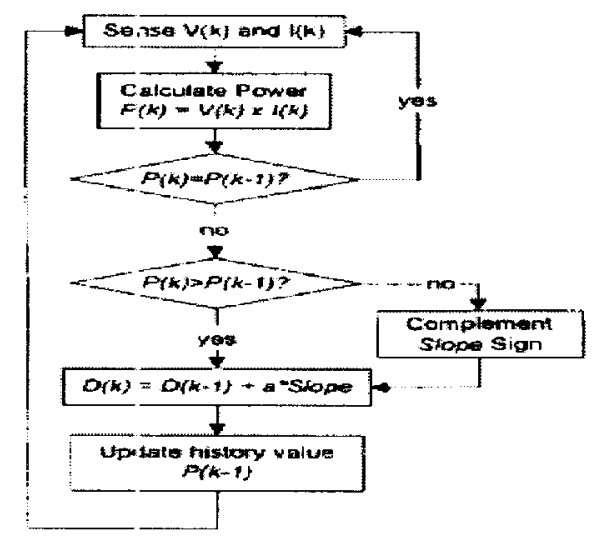

Figure 13. Block Diagram Representation of HCS Method

The primary advantage of this method is its simplicity and independence from wind turbine characteristics. However it has many disadvantages. HCS method works 
well only in cases of constant or slowly changing wind speeds and it can even cause smaller wind turbines to stall (Wai \& Lin, 2006), (Yaoqin, Zhongqing, \& Binggang, 2002). Besides, it also leads to slow tracking if the step size is low and on the converse, leads to hunting around peak power value if the step size is high (Yaoqin, Zhongqing, \& Binggang, 2002).

\subsubsection{Tip Speed Ratio (TSR) Method}

TSR method tries to changes modify the rotational speed of generator so as to maintain an optimum TSR mentioned in Chapter 2. The limitation of this method is that wind speed needs to be known along with the turbine rotational speed measurements. This adds to the system cost, especially when considered for use with small-scale wind turbines.

\subsubsection{Power Signal Feedback Method (PSF)}

PSF method uses a reference power, which is the maximum power at that particular wind speed. This in itself presents an issue, as the prior knowledge of the wind turbine characteristics and wind speed measurements is required. Once this reference power is obtained from the power curve for a particular wind speed, a comparison with the present power yield is done. The error produced then drives a PI control algorithm. PI control refers to Proportional (P), Integral (I) control. It has a P and I part that are manipulated to reduce the error between a known set point and the instantaneous values of the measured values (here power). Figure 14 shows how the PSF method is used for a wind turbine. 


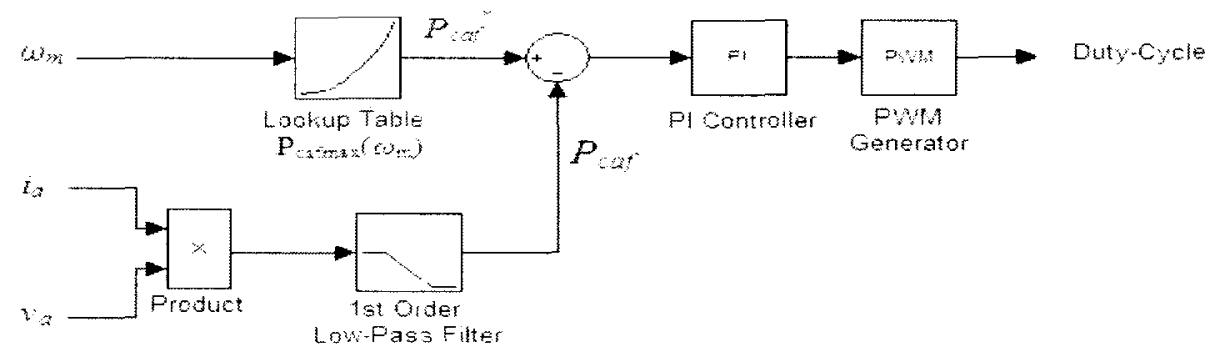

Figure 14. PSF Method Block Diagram (Adegas, Alé, Reis, Simioni, \& Tonkoski, 2006)

Besides the aforementioned conventional methods, numerous derived or hybrid methods exists that improved the performance of the existing conventional methods. A brief description of these methods is being done in the coming section.

\subsection{OTHER WORK IN WECS MPPT ALGORITHMS}

MPPT algorithms have been a topic of keen interest to many research activities. This section gives a summary of the major efforts in the field of MPPT applied to wind energy conversion systems.

Many researchers like (Hua \& Geng, 2006), (Wasynezuk, 1985) have exposed the inherent flaws with HCS method. Hua \& Geng suggest that PSF solves some issues presented by HCS method such as the fluctuation in output power.

Moor \& Beukes, (2004), proposes an innovative way to tackle the limitations presented by HCS. It proposes a method to track the optimal loading on the generator as a possible solution. To implement this, the paper takes two approaches referred to as the Anemometer Approach and Calculation Approach methods. Anemometer approach 
preprograms different wind speeds and the corresponding loading. Then an anemometer can be used to measure the wind speed and apply the required load. The paper states that this method gives satisfactory performance even if there is some amount of tracking inefficiency. Another method adopted by the paper is the Calculation Approach (CA). It makes use of the fact that the synchronous machine rotational speed and the electrical frequency are directly proportional. From the performance graph, wind speed can be found and the same method as suggested in the anemometer method can be employed. An alternative approach taken in the subject of adaptive algorithms is that of Tafticht, Agbossou, \& Cheriti, (2006), where a small improvement was made in the HCS algorithm. The algorithm addresses the issue of oscillations at peak power. Once the operating point moves beyond the peak to reduce the power (i.e., right side of the powerrotor speed curve), this algorithm doubles its step size and pushes it back to the left side of the power versus rotor speed graph.

Application of Fuzzy logic in MPPT has been talked about by Hilloowala \& Sharaf, (1996). The maximum power at different wind velocities is calculated and an equation relating the same was derived by

$$
P_{\text {max }}=-3+1.08 V_{w d}-0.125 V_{w d}^{2}+0.842 V_{w d .}^{3} .
$$

Where, $P_{\max }$ is the maximum power and $V_{w d}$ is wind velocity. The reference power at rectifier output is given as

$$
P_{\text {rec }}=n_{g} \cdot n_{r} \cdot P_{\max }
$$

Where $\eta_{\mathrm{g}}$ is generator efficiency, $\eta_{\mathrm{r}}$ is the rectifier efficiency. 
The actual power output of the rectifier $P_{o}$ is compared to the reference power, and any mismatch is used by the fuzzy logic controller to change the modulation index $M$. The input signals to the fuzzy logic controller are the wind velocity, and the power output of the rectifier $P_{o}$. These are used to find the error and the rate of change of error. The controller output voltage is determined by fuzzification of the input variables. Next, a set of fuzzy rules (49 in number) is compared against it and then the output modulation index is determined accordingly as

$$
M_{K+1}=M_{K}+\Delta M
$$

$M_{K+1}$ refers to the modulation index at next instant, $M_{K}$ is the current modulation index and $\Delta M$ is the change in modulation index.

Now a voltage in proportion to this modulation index is produced and transmitted through a data translation card to control a PWM output. However, according to Koutroulis \& Kalaitzakis, (2006), this method has disadvantages such as accuracy reduction and need for a high precision anemometer. System complexity is also increased due to the fact that when the wind gusts are of a low energy profile, there is a need for extra processing for accuracy.

This chapter has framed the questions the thesis answers and gives a brief collection of major works done in this area. It mentions that many research efforts, like those by Hua \& Geng, (2006), Wasynezuk, (1985) have discussed the limitations of employing the traditional HCS algorithm. Many papers have tried to find answers to these issues using their own approaches. While the application of Neural systems and Fuzzy logic as proposed by Spee, Bhowmik, \& Enslin, (1994) and Hilloowala \& Sharaf, 
(1996), respectively, produce issues like increased system complexity and reduction of accuracy. Some algorithms like the one proposed by (Moor \& Beukes, 2004) make use of preprogramed turbine characters. Even though some methods like PSF method were found to be a good substitute for HCS, again these algorithms require wind speed calculation, which adds to system cost and requires turbine characteristics. Hence, these algorithms cannot be used for another turbine or do not take into account the wear and tear that can take place to a turbine. 


\section{CHAPTER 4}

\section{PROBLEM DEFINITION}

\subsection{PROBLEM DEFINITION}

This section outlines the questions to which this thesis tries to find an answer to. As seen in section 3.2 and quoted by Yaoqin, Zhongqing, \& Binggang, (2002), Wai \& Lin, (2006), and Raza, Goto, Guo, \& Ichinokura, (2008), there are several limitations that can be identified in the application of HCS method to WECSs. These can be summed up as in following sections.

\subsubsection{Step Size Trade Offs}

Normal HCS methods takes samples of the power and compares sample at $K^{t h}$ instant to the $(K-1)^{t h}$ sample. It then increases the duty cycle if there is an increase in power or decreases the duty cycle if there is a reduction in power. However, the increments/decrements given to the duty cycle are fixed. Once the peak is detected there are oscillations around the peak power. This is being demonstrated in Figure 15. Also if the step size is made large then the value of $\Delta P$ increases in Equation 4.1 while if it is too low then the tracking time suffers. The efficiency of an MPPT algorithm (Femia, Petrone, Spagnuolo, \& Vitelli, 2005) is given as: 


$$
\% \eta_{\text {max }}=\left(1-\Delta P / P_{\text {mppt }}\right) \cdot 100 \%
$$

Where $\Delta \mathrm{P}$ is the change in power due to oscillations and $P_{m p p t}$ is the power at maximum peak.

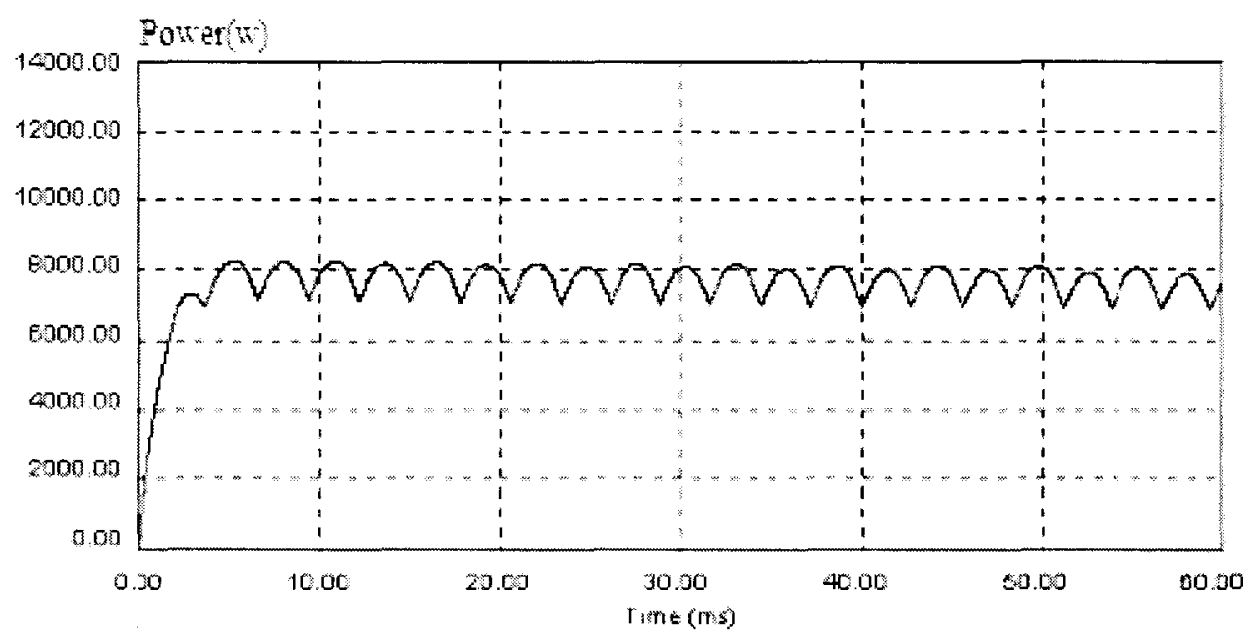

Figure 15. Oscillations in peak power using traditional HCS method (Tafticht, Agbossou, \& Cheriti, 2006)

The traditional HCS method was simulated to illustrate the above said limitations. Simulations were done using MATLAB-SIMULINK for a constant wind speed. The wind velocity changes at the instant when time is 0.5 seconds. Shown in Figure 16 is the effect of a small fixed duty cycle in power point tracking. The plot describes the situation where the duty cycle increments are fixed and small but then the number of steps taken to detect the peak is more. Hence the time taken to detect the peak was found to be 0.05 seconds but with minimal oscillation. 


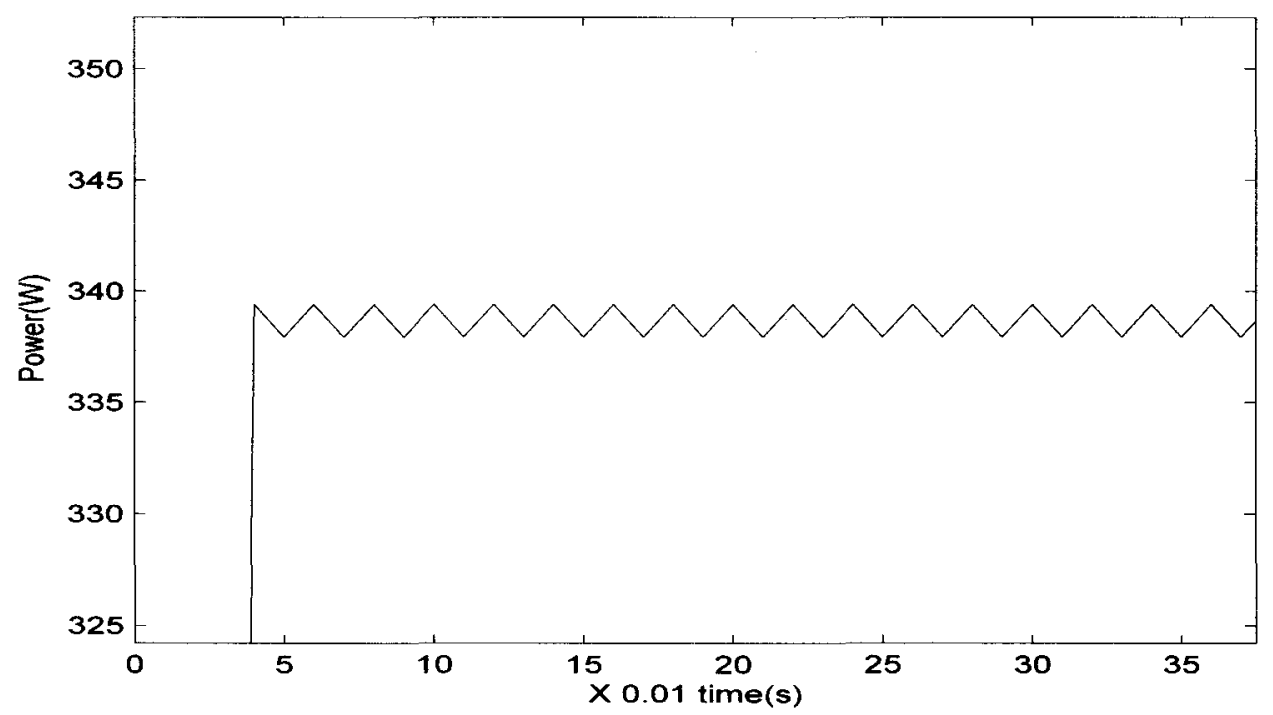

Figure 16. Effect of Smaller step size on MPPT

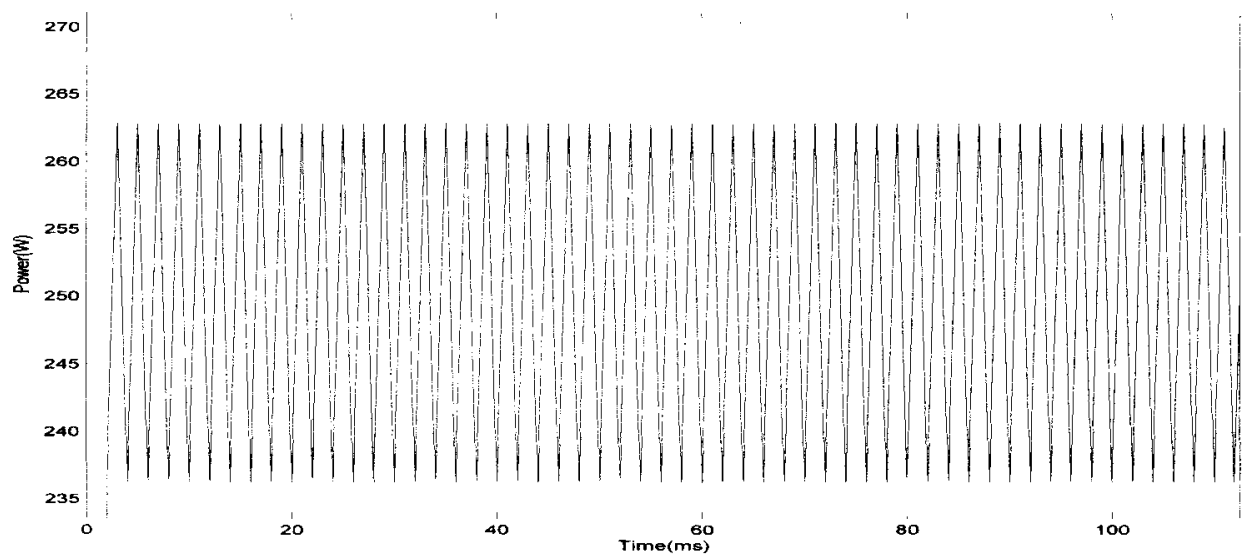

Figure 17. Effect of larger duty cycle on power point tracking

Figure 17 shows the case when a larger fixed duty cycle is used leading to a negative dip in power equivalent to $\Delta \mathrm{P}$ and the oscillations aroused due to this would be 
equal to $\Delta \mathrm{P}$. The tracking time is reduced to 0.001 seconds but notice the oscillations formed once the peak is detected.

\subsubsection{Tractability under rapidly varying wind conditions}

A severe limitation of the HCS method is its inability to track the maximum power point in cases of abruptly varying wind conditions. Unfortunately in real world applications, wind speeds often vary abruptly. The reason for this error is that HCS method only takes into account the change in power due to the last perturbation for a power change. It neglects the fact that there could be wind changes leading to a power change. For example, if the wind speed suddenly decreases, the peak power is lower than the present peak power. But as HCS does not take into account the wind change, it interprets this lowering of power due to the perturbation and hence reverses the direction of search. This leads to incorrect decisions when there is a change in velocity of wind. This thesis develops a solution to the limitations with HCS method mentioned in Sections 4.1 .1 and 4.1 .2 by the usage of a variable duty cycle. 


\section{CHAPTER 5}

\section{MODIFIED HCS ALGORITHM AND METHODS OF SIMULATION}

The proposed algorithm uses an adaptive step size, which is a modification of the classical HCS approach to overcome the limitations discussed in Section 4.1.1. Similar adaptive algorithms have been applied to solar energy conversion systems with some success. This chapter defines the new algorithm and the mathematical models used in its simulation and testing. A background of the simulation environment (MATLABSIMULINK) has also been provided. In the latter Sections of the chapter, the major simulation results observed have been depicted and talked about.

\subsection{PROPOSED ALGORITHM}

A novel algorithm is proposed which has the benefits of HCS, while eliminating the limitations of the HCS method. Some of the assumptions made as the algorithm is proposed are as follows. Continuous operation of the turbine is assumed, which means that the boost converter is in continuous operation mode. Also the mechanical characteristics of the turbine-generator set, e.g. inertia, have been discarded. The proposed algorithm maintains a similar approach to HCS method. This is to ensure that the simplicity associated with the HCS method is preserved. 
Another characteristic of the proposed algorithm is an adaptive duty cycle, in contrast to the HCS method where the duty cycle is constant throughout the search. The step size is constant as in HCS method until the search is within close vicinity of the peak power. Once the search has approached the peak, the step cycle is adaptively adjusted. If the last operating point is on the positive slope side of the power curve, the increment in duty cycle is reduced to $25 \%$ of its present value. While if it had already crossed the peak but still in close vicinity of the peak power, then the direction of perturbation is changed and again the same process is repeated.

The process can be better understood by noting Equation 5.1.The initial constant value of increment for $a_{k}$ in the equation is set to 0.1 . This high value was chosen keeping in mind that the perturbation has to be fast. This will be its value at all other times except when the peak has reached to aid faster tracking. To increment or decrement the duty cycle, a direction variable $\left(S_{i}\right)$ with initial value $=1$ was used. In case the duty cycle had to be increased the value of this variable stood the same while if the direction had to be reversed then it is multiplied by -1 .

$$
D_{p}=D_{o}+0.01 \cdot D_{o} \cdot a_{k} \cdot S_{i}
$$

As the search reaches the vicinity of the peak power, the value of $a_{k}$ is changed adaptively as previously stated. Suppose the operating point had been perturbed beyond the peak power already, then a method similar to the one employed by Tafticht, Agbossou, \& Cheriti (2006) is used to pull the operating point towards the left side by changing the direction and increasing the step size. This is done by increasing the incrementing factor to 0.2 . This section ensures that the there are no or very little 
oscillations involved in the power once the peak is detected. Another feature the proposed algorithm adds to the traditional HCS is the ability to detect if the change in power levels was due to a change in wind speed rather than assuming it is a result of the previous perturbations. This was done by comparing two recent values of wind speeds using the memory block of SIMULINK so that the previous value can be stored and compared. In practical applications, a microcontroller can be applied to store these previous values. This would make sure that the algorithm accounts for the change in wind conditions during varying wind conditions.

A more detailed idea of the proposed algorithm can be gained referring to Figure 18. Shown in Figure 18 are the steps involved in the proposed algorithm. The first step in the algorithm is to collect the instantaneous voltage $\mathrm{V}$, instantaneous current $\mathrm{I}$, present direction of perturbation $S_{i}$ (set to 1 initially), present increment factor $a_{k}$, pervious duty cycle $D_{o}$. The next step in the process is to obtain the current instantaneous power $P_{k}$ given as the product of the voltage (V) and current (I) sampled in the previous step. Next a check has been done to verify that there is no change in wind velocity over the two sampling instants.

Once the wind speed was found to be equal, then the algorithm functions by checking three conditions said in Equations 5.3 and 5.4. 


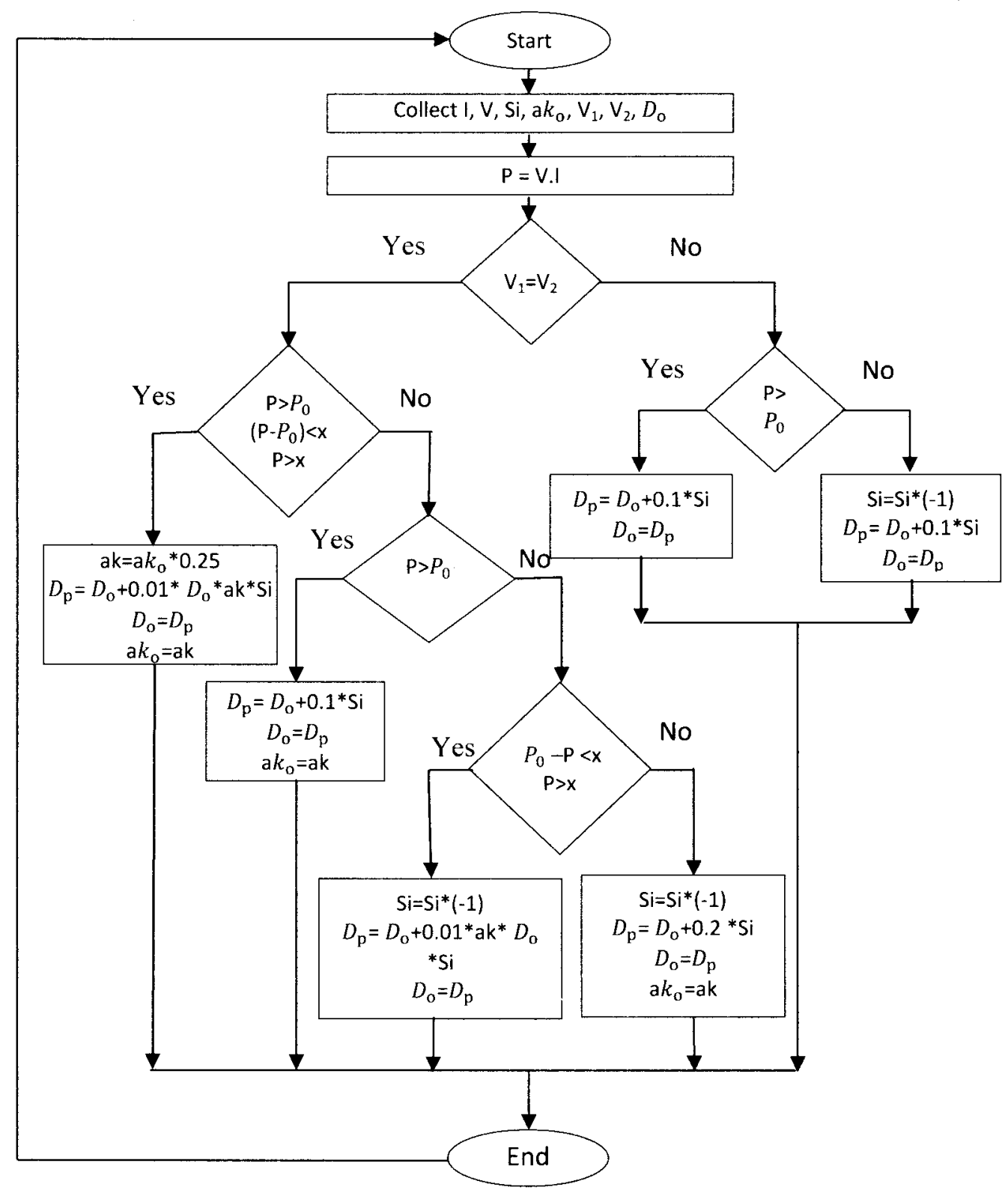

Figure 18. Proposed Algorithm Flow chart 
The first condition is to make sure if the power has increased over the sampling time. Second condition confirms that the power increase due to the last perturbation is less than a chosen small value. This check ensures that the peak of the power curve is reached near the peak point, as then the power increase over a perturbation lowers due to the decreasing slope of the curve and due to the fact that as the peak point of the curve is approached, the duty cycle increment is reduced.

If both the above said conditions are found to be true, the algorithm reduces the increment factor $\left(a_{k}\right)$ to $25 \%$ of its present value as it has detected proximity of the peak. Then the duty cycle is incremented as in Equation 5.5

$$
D_{p}=D_{o}+D_{o} \cdot 0.01 \cdot a_{k} \cdot S_{i} \text {. }
$$

The direction of perturbation is still the previous direction as the power is found to be increasing and hence there is no need to change the direction of perturbation. After this increment is done, the algorithm stores the present values of duty cycle, increment and sign as previous values for the next sampling instant.

If any of the conditions (Equation 5.3 and Equation 5.4) are found to be false, then the algorithm checks if the power has increased over the sampling period, i.e., if Equation 5.3 was true. If this gives a true value, the direction of perturbation is correct but it is not near the peak power. Hence, there is no change made to the sign variable or the increment factor, and the duty cycle is incremented by $10 \%$, which saves tracking time due to the increased step size. As in the previous case, the previous values are updated for use in the next sampling instant. 
Next, the block diagram defines the actions to be taken in case Equation 5.3 was false but Equation 5.4 was true. In this case, the power tracked is beyond the maximum power point and in the negative slope. In such a case, the algorithm checks how far beyond the peak, is the present power point. This is done by checking if the power difference is still in the chosen range but this time at the right side of the peak. This is expressed in Equation 5.6.

$$
\text { Po-P }<\mathrm{X}
$$

If Equation 5.6 is found true, then the algorithm is sure that the last perturbation has not caused the operating point to go too far beyond the required maximum power point. The value for $\mathrm{x}$ was selected as $30 \mathrm{~W}$ in this simulation following a trial and error method for this turbine size. This scenario has been depicted in Figure 19.

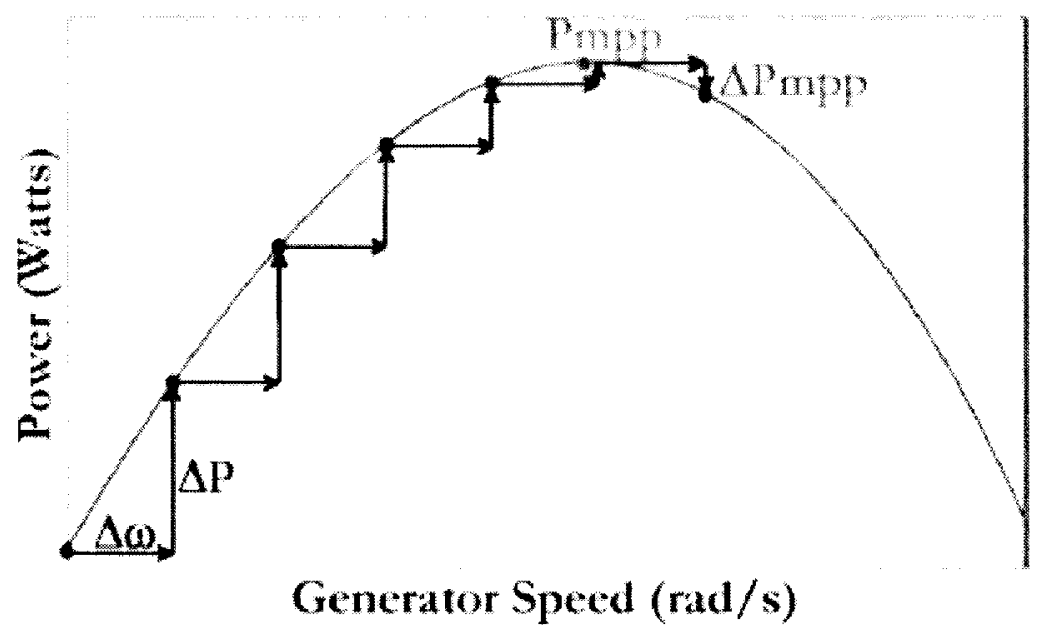

Figure 19. Operating Point just beyond the Peak

Hence, the duty cycle increment is reduced to $25 \%$ of its initial value. Since the power produced has reduced, corrective action is taken by the algorithm in the direction of perturbation. It negates the present direction by changing the sign of $S_{i}$ variable. Now 
the duty cycle is incremented in Equation 5.5, except for the fact that there is a change in direction variable $S_{i}$ and the incrementing factor $a_{k}$. Next, the previous values are updated for use in the next instant.

If condition 5.6 is found to be false, the algorithm assumes that the present power point is far from the peak and in the right hand side of the power curve as depicted in Figure 20. Corrective action is taken and sign variable is manipulated to reverse the direction and the incrementing factor is changed to 0.2 and previous values are updated for future use.

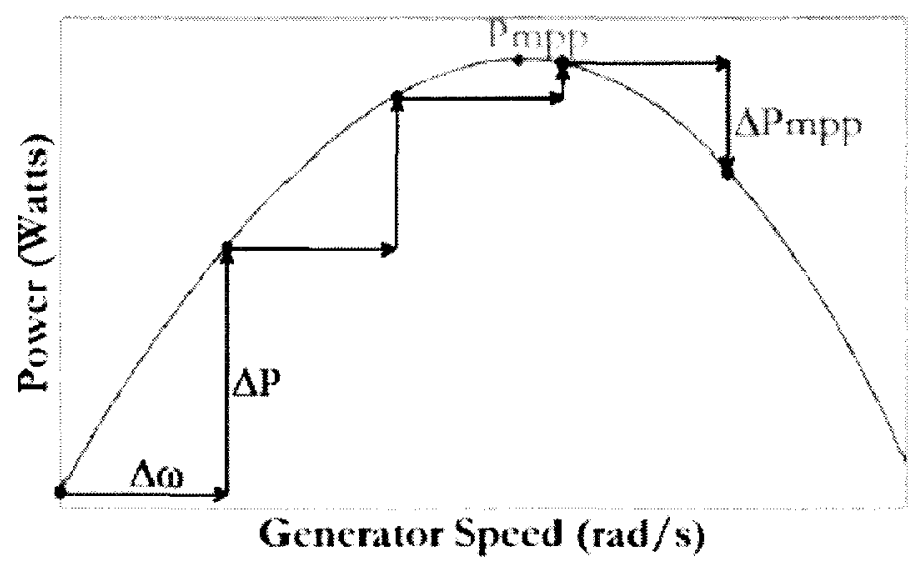

Figure 20. Operating Point Far Beyond Peak Power

Note that the above course of action took place if the wind speeds over the two sampling instants were equal. In a scenario where the wind speeds have changed, the perturbation checks if the power has increased after this change in wind speed. If there was an increase in power, then the duty cycle is incremented by $10 \%$, or if the power decreased, the duty cycle is reduced by $10 \%$. In both the above cases, the previous values are updated as before. 


\subsection{SIMULATION ENVIRONMENT}

Wind MPPT algorithms in the past have been simulated using a number of software based on the purpose of simulations. Some of the popular ones are PSIM, MULTISIM, CASPOC, PSPICE and MATLAB-SIMULINK. Of the above PSIM, MATLAB along with SIMULINK and the SIMPOWERSYSTEMS toolbox are the most effective and widely used ones.

MATLAB-SIMULINK was used to simulate the proposed MPPT algorithm. It is a high level language and does computationally intensive works very efficiently. It is also user friendly including with many predefined blocks. Even though few predefined blocks were used in the final forms of this thesis, initial tests used a lot of standard blocks. Another impressive feature that MATLAB-SIMULINK provides is that it allows one to code an algorithm inside the same console unlike PSIM where an algorithm has to be coded in a separate $\mathrm{C}$ compiler and then a DLL file is made which is called as the program is run. Along with it, MATLAB-SIMULINK has a lot of features like memory blocks that are vital for an algorithm like the one in this thesis where lot of comparisons and past values are required. Also, there is a data transition block, which ensures that no data loss is incurred as different blocks operate at different sample speeds. All of these features led to the selection of MATLAB-SIMULINK as a simulation environment for the thesis. In the following section, the mathematical models used to simulate the different components of WECS have been explained. 


\subsection{MATHEMATICAL MODELING OF THE WIND ENERGY CONVERSION}

SYSTEM

The various components used in the simulation include Wind Turbine, PMSG, Rectifier, Power Electronic Converter and the PWM generator block. Described in the coming sections are their mathematical models.

\subsubsection{Wind Turbine}

For simulation purposes, a variable-speed wind energy conversion system was used. Figure 21 shows the characters (Power versus rotor speed) of the wind turbine used in thesis.

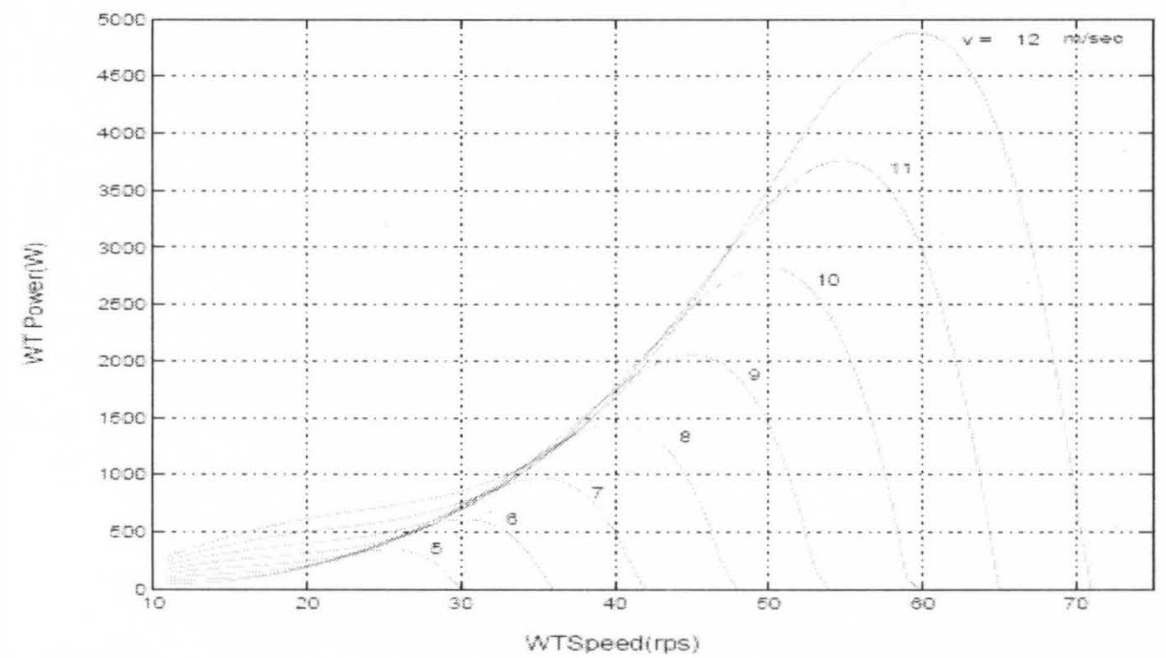

Figure 21. Characteristics of the Simulated Wind Turbine (Raju, Fernandes, \&

Chatterjee, 2011)

It is designed for wind speeds ranging from $5 \mathrm{~m} / \mathrm{s}$ to $12 \mathrm{~m} / \mathrm{s}$ with peak power being $4.75 \mathrm{KW}$ approximately at $12 \mathrm{~m} / \mathrm{s}$. As stated in section 2.1 , wind turbine tip speed ratio, TSR is given as 


$$
T S R=R \cdot \omega / v_{\mathrm{wd}}
$$

Figure 22 shows the variation of $C_{p}$ with TSR. It can be seen that the peak value of $C_{p}$ is found to be 0.42 when TSR=7.5. The relationship between $\mathrm{Cp}$ and TSR was modeled as done by Borowy and Ziyad (Borowy \& Ziyad, 1997).

The output power given by the turbine is given by the equation

$$
P t=0.5 v_{w d}^{3} \cdot A \cdot \rho \cdot\left(C_{p}\right)
$$

Substituting the value for wind velocity from equation (5.7), Equation 5.9 becomes

$$
P_{t}=0.5 A \rho\left(C_{p}\right) \Pi R^{5} \omega^{3} /(T S R)^{3} .
$$

Torque coefficient of wind turbine is denoted as $C_{t}$ is given as

$$
C_{t}=C_{p} / T S R
$$

An important thing to be noted here is that for optimal power extraction, $P_{t}=$ $K \omega^{3}$ as other factors become constant. This means that if the rotor speed is controlled, power can be controlled (Raju, Fernandes, \& Chatterjee, 2011). Torque supplied by the wind turbine to the generator is given by equation

$$
T_{t}=P_{t} / \omega
$$

On substituting values from Equations (5.7), (5.10) in (5.12), another important equation is obtained as below.

$$
T_{t}=0.50 A \cdot \rho \cdot R \cdot V_{w d}^{2} \cdot d^{2} \cdot C_{p} / T S \mathrm{R}
$$


Equations (5.7), (5.8), (5.10) have been employed in the simulation of wind turbine in this thesis.

\subsubsection{Permanent Magnet Synchronous Generator (PMSG)}

The wind turbine is connected to PMSG by gears. This produces an equivalent voltage that is sent to the rectifier. The produced EMF is given by the equation

$$
E=K \cdot \Omega_{g}
$$

Where $\Omega_{g}$ is the rotational speed of the generator and $\mathrm{K}$ is the generator constant which can be specified as volt produced with no load/RPM. The terminal voltage of a generator is denoted by $\mathrm{V}$

$$
V=E-I_{g} \cdot R_{a}-X_{s} \cdot I_{g}
$$

Where $R_{a}$ is the generator armature resistance and $X_{s}$ is the synchronous impedance. $I_{g}$ is given by the following equation

$$
I_{g}=E /\left(\left(R_{a}\right)+j X_{s}\right)
$$

Where, $R_{g}$ denotes the terminal impedance of the generator.

The Power output considering a three phase system is given by the following equation:

$$
P=3 V \cdot I_{g} \cdot \operatorname{Cos} \emptyset
$$

Where, $\operatorname{Cos} \emptyset$ is the power factor. The value for $\Omega g$ is related to the wind turbine speed by the following equation:

$$
\omega=2 \Omega_{g} /(\mathrm{P} \cdot \mathrm{G})
$$


Where, $P$ is the number of Generator poles and $G$ is the gear ratio of the gear employed.

Table 1. Simulation Parameters-Turbine and Generator

\begin{tabular}{|l|l|}
\hline Air density & $1.08 \mathrm{Kg} / \mathrm{m}^{2}$ \\
\hline Radius & $1.525 \mathrm{~m}$ \\
\hline Gear Ratio & 5 \\
\hline Rated power & $1500 \mathrm{~W}$ \\
\hline Rated wind velocity & $8 \mathrm{~m} / \mathrm{s}$ \\
\hline Generator Poles & 4 \\
\hline Motor coefficient & $0.314 \mathrm{volts} / \mathrm{rad} / \mathrm{sec}$ \\
\hline
\end{tabular}

\subsubsection{Rectifier and DC-DC converter}

The rectifiers convert the alternating terminal voltage the generator produces into a DC voltage. This is then boosted to another voltage level using a DC-DC converter. Supposing that the peak line to line voltage that is formed towards the rectifier input is $V_{\text {peak }}$, the DC voltage output by rectifier is given as:

$$
\begin{aligned}
& V_{d c}=(3 / \pi) \int_{-\pi / 6}^{\Pi / 6} V_{\text {peak }} \cos \emptyset \mathrm{d} \emptyset \\
& =(3 / \text { п) }) V_{\text {peak }} \\
& =(3 \sqrt{2} / \pi) V_{l-l} \\
& =(3 \sqrt{6} / \pi) V_{l-l}
\end{aligned}
$$


Where $V$ is the generator terminal voltage and $V_{l-l}$ is line-to-line instantaneous voltage.

Similarly current relations are given by

$$
I_{D C}=(\Pi / \sqrt{6}) I_{g} .
$$

Equations 5.23 and 5.24 were used to model the rectifier in the simulation.

The choice of the type of converter is determined by the voltage required at the output. The thesis simulates a boost converter boosting the voltage output to $500 \mathrm{~V}$. The choice of output voltage is highly dependent on the application. For example, the voltage required to charge a battery used along with the system may dictate output voltage. This thesis opted for a $500 \mathrm{~V}$ output voltage following the efforts of R. Bharanikumar and A. Nirmal Kumar (Bharanikumar \& Nirmal Kumar, 2010). The boost converter was modeled by the equation relating its output voltage and the input voltage.

$$
V_{\mathrm{o}}=V_{s} /(1-D)
$$

The test load impedance was chosen to be $500 \mathrm{ohms}$ nonreactive and hence the current flowing can be easily calculated using the formula

$$
I_{o}=V_{\mathrm{o}} / 500 .
$$

Equations 5.19 and 5.20 were used to model the power electronic converter.

\subsection{SIMULATION RESULTS}


A number of wind conditions were simulated and satisfactory results were obtained with the output voltage being constant and the power yield following the peak power in the power curves of the turbine being simulated (refer Figure 21). All the simulations were run with a sampling time of 0.0001 seconds.

\subsubsection{Performance in Constant Wind speed}

A constant wind speed of $5 \mathrm{~m} / \mathrm{s}$ was chosen to be the input to test the algorithm efficacy in a low constant wind speed.

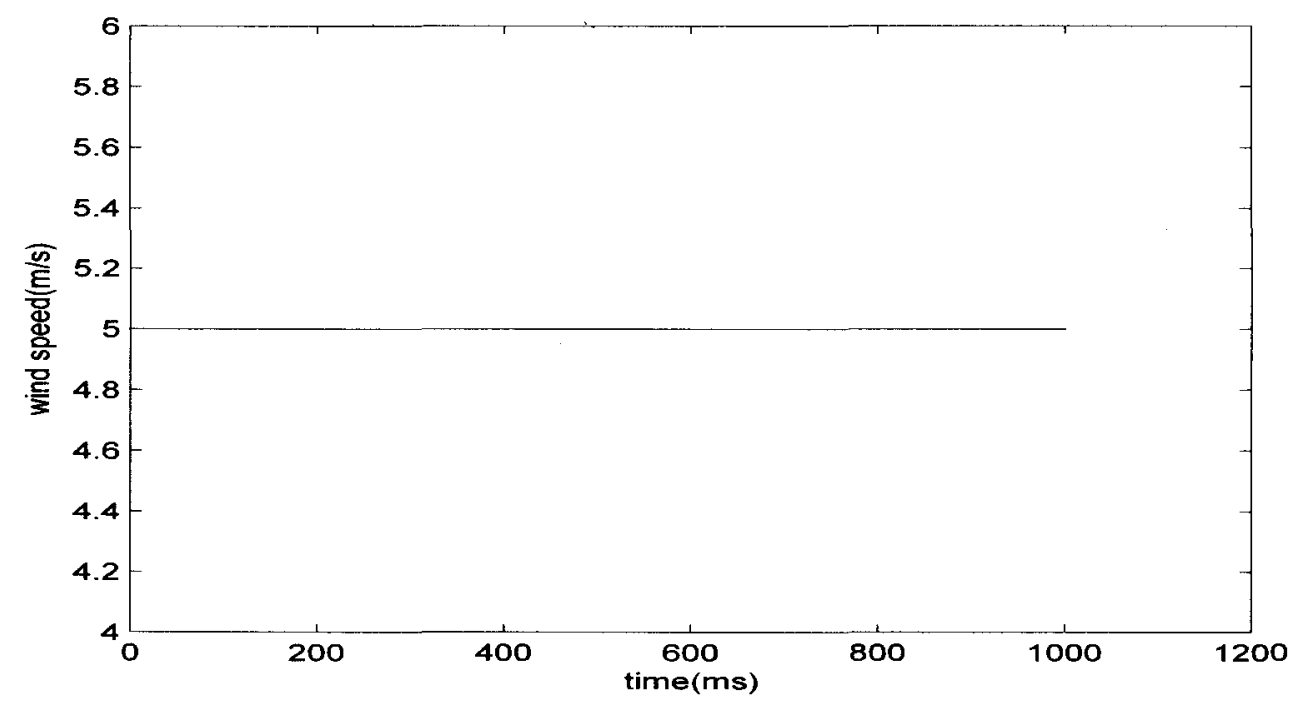

Figure 22. Constant Wind Speed Profile $(5 \mathrm{~m} / \mathrm{s})$

Figure 22 shows a constant wind speed of $5 \mathrm{~m} / \mathrm{s}$ simulated to test the algorithm efficiency at constant wind speed. 


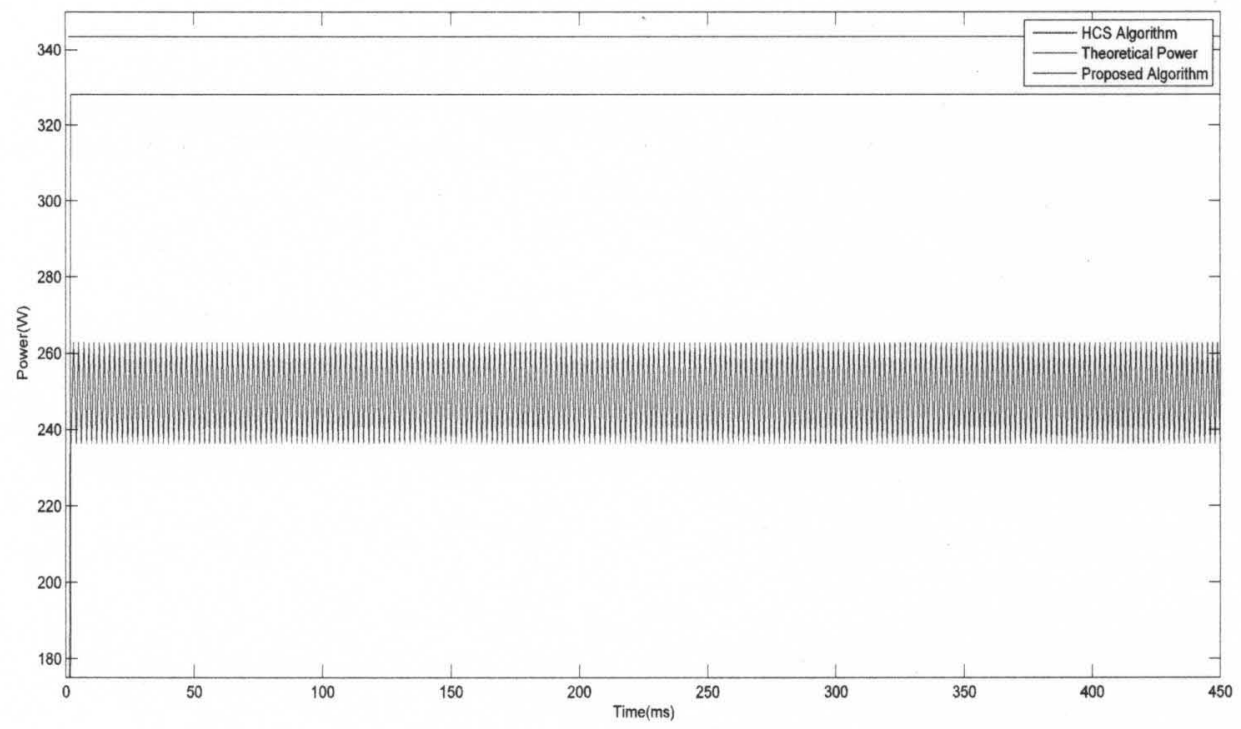

Figure 23. Output Power- Constant Wind Profile

Figure 23 shows a comparison of extracted power levels while the proposed algorithm was used against the HCS algorithm. It can be seen that the maximum power extracted is $328 \mathrm{~W}$ using the proposed algorithm. For a wind velocity of $5 \mathrm{~m} / \mathrm{s}$, the wind characteristics shown in Figure 21 show that the peak power should be approximately $343.5 \mathrm{~W}$. The efficiency of a turbine employing the proposed algorithm is $95.48 \%$ for a wind velocity of $5 \mathrm{~m} / \mathrm{s}$ against the HCS algorithm, which operates at an efficiency of 76.27\%. A notable achievement here is that there are no oscillations once the peak is detected when compared with the bottom figure which showcases the performance of traditional HCS in similar settings.

Shown in Figure 24 is the voltage output at the end of the rectifier stage. This voltage is boosted to $500 \mathrm{~V}$. 


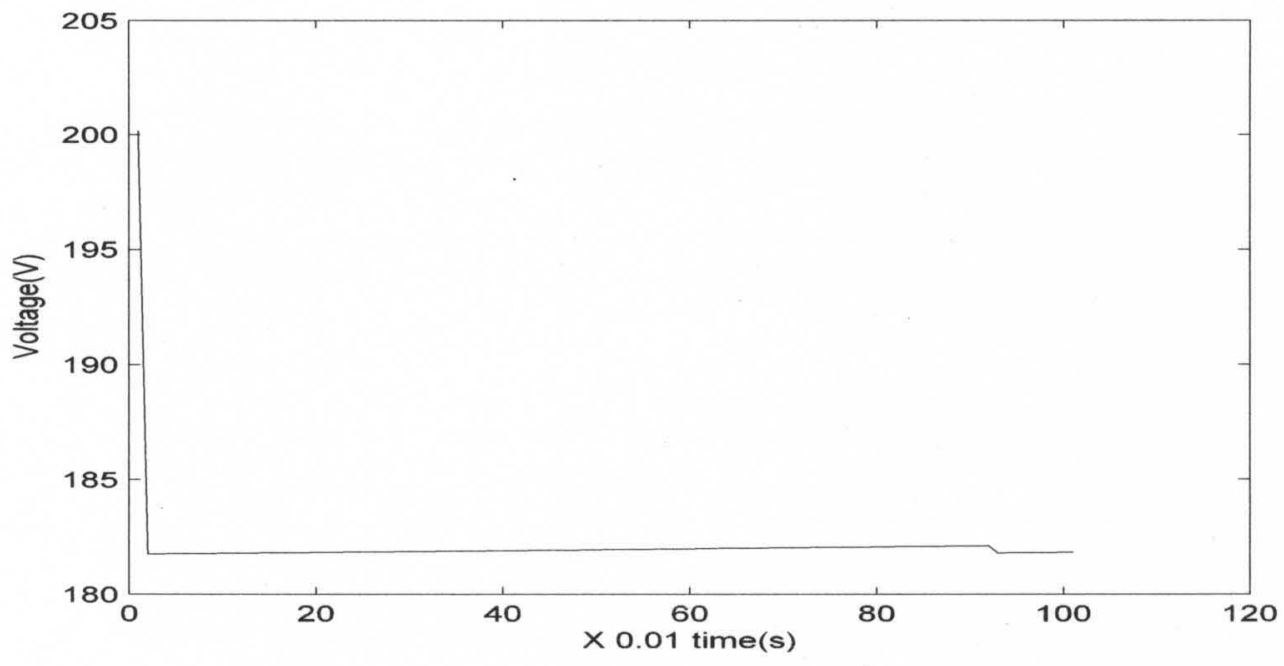

Figure 24. DC Link Voltage-Constant Wind Profile

The required output voltage at the output end was $500 \mathrm{~V}$ as per the design. Referring to Figure 25, the output voltage is found to be regulated to $500 \mathrm{~V}$.

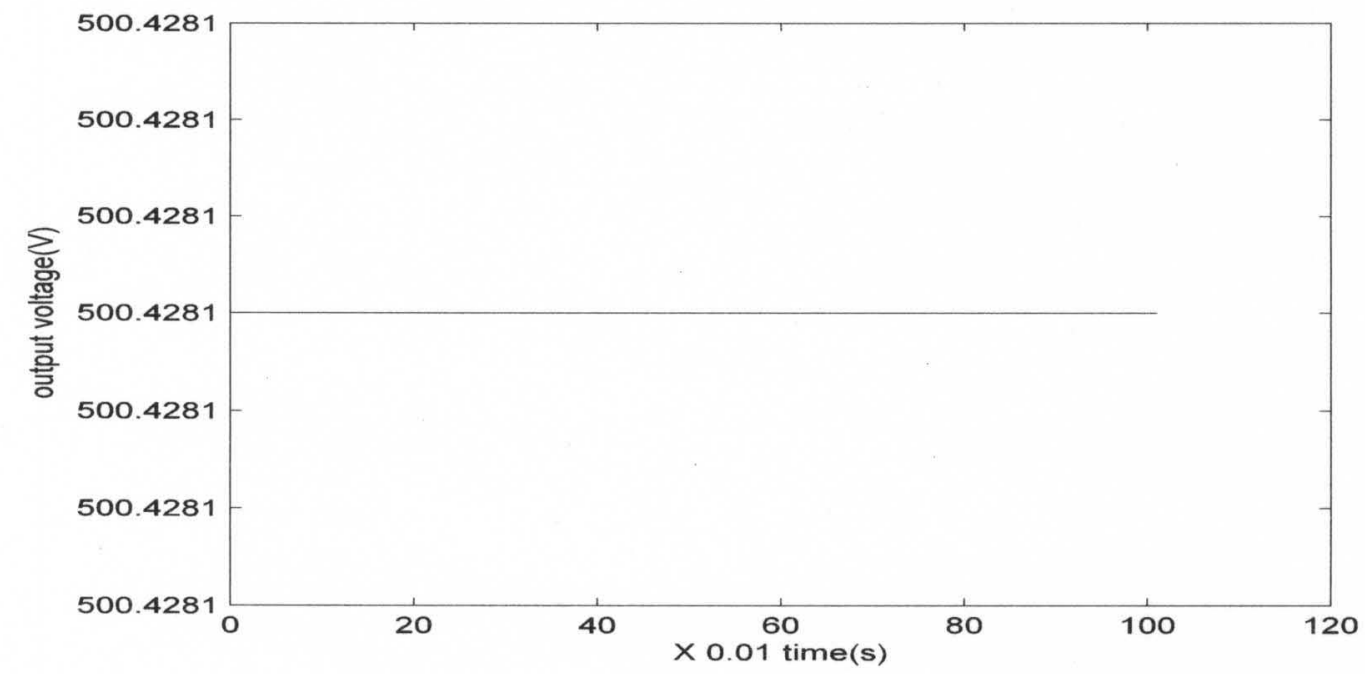

Figure 25. Regulated DC Voltage-Constant Wind Profile

The above results prove that the proposed algorithm is efficient in eliminating the oscillations at peak power levels for a constant wind speed. 


\subsubsection{Performance in Abrupt Wind speed change}

A step reduction of wind was simulated to find the efficiency in case of abruptly changing wind profile. Shown in Figure 26 is the simulated wind profile.

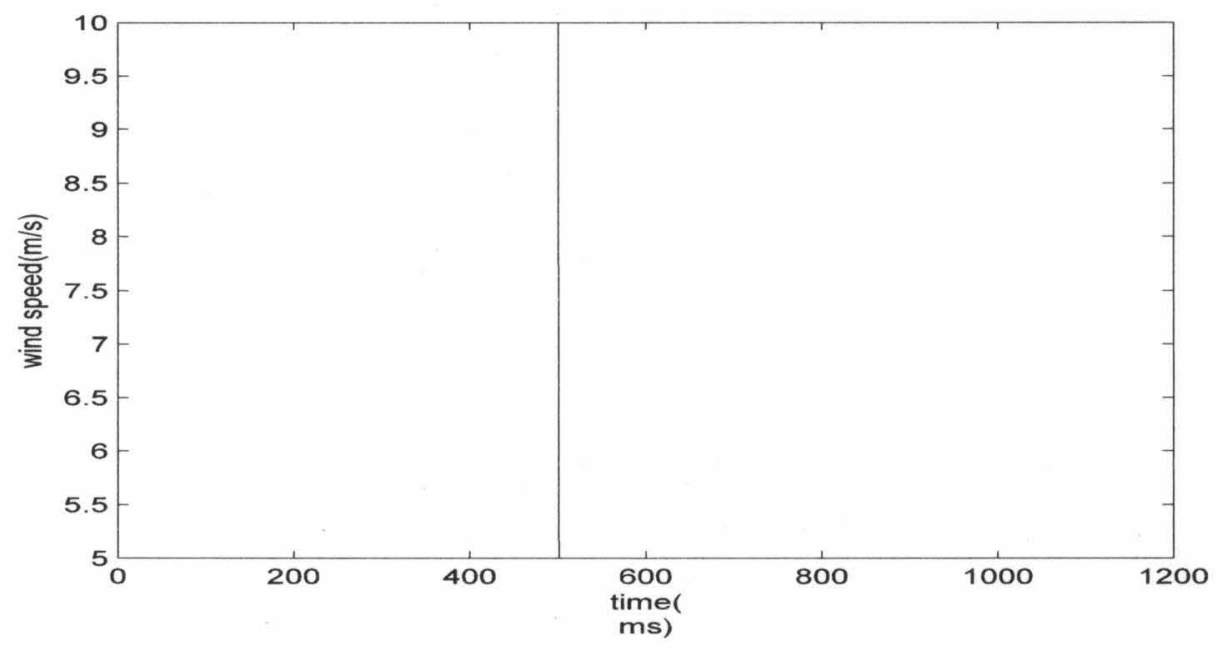

Figure 26. Simulated Wind Profile-Abrupt Wind Speed

As seen in Figure 26, the wind velocity stays constant at $10 \mathrm{~m} / \mathrm{s}$ for 0.5 seconds while it drops to $5 \mathrm{~m} / \mathrm{s}$ for the second half of the simulation.

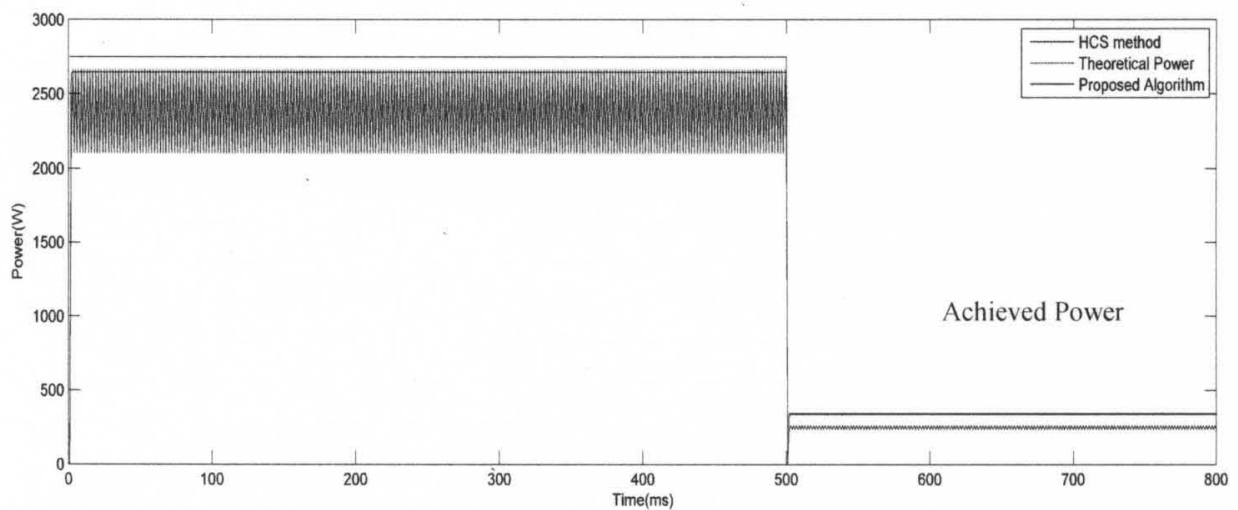

Figure 27. Turbine Power-Abrupt Wind Speed Change (using proposed system and HCS method) 
Figure 27 shows the extracted power, which is approximately $2647 \mathrm{~W}$ when the wind speed is $10 \mathrm{~m} / \mathrm{s}$, and $336.5 \mathrm{~W}$ at a wind speed of $5 \mathrm{~m} / \mathrm{s}$. However, the expected values are $2750 \mathrm{~W}$ and $343.5 \mathrm{~W}$ respectively. This means that the proposed algorithm has shown efficiencies of $96.25 \%$ and $97.96 \%$ at $10 \mathrm{~m} / \mathrm{s}$ and $5 \mathrm{~m} / \mathrm{s}$ respectively. This results in an average efficiency of $97.11 \%$. When the HCS algorithm was implemented, the efficiencies dropped to 86.36 and $76.27 \%$ for these two wind velocities. The proposed algorithm showed no ripple once the peak had been detected. There were also no incorrect perturbations performed during the change in wind velocity, which is a remarkable achievement of the proposed algorithm.

The output voltage at the load end is shown in Figure 28. This has been recorded to be equal to $500.4 \mathrm{~V}$, which is approximately the expected value of $500 \mathrm{~V}$.

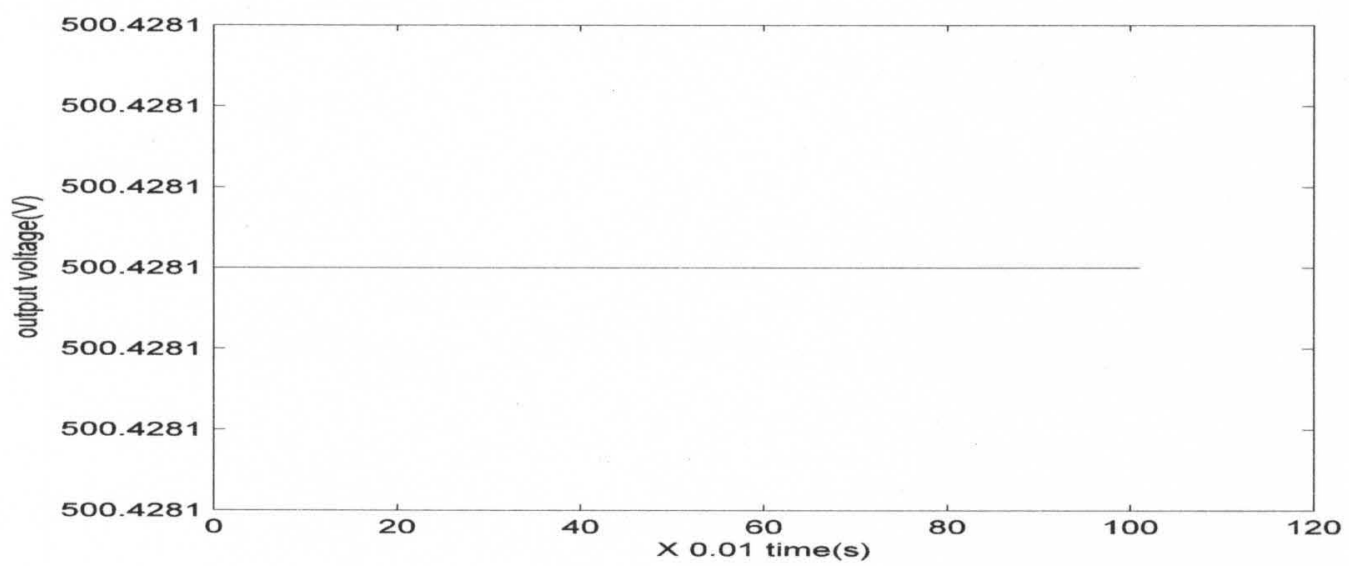

Figure 28. Regulated Output Voltage during Abrupt Wind Speed Change 


\subsubsection{Performance in Randomly Varying Wind Speed}

A randomly varying wind profile was used to test the effectiveness of the algorithm under continuously varying wind conditions. Figure 29 shows the input waveform employed to simulate a constantly varying wind profile. The profile was made using the 'random signal' block in MATLAB-SIMULINK with values ranging between 5 $\mathrm{m} / \mathrm{s}$ to $12 \mathrm{~m} / \mathrm{s}$. The different velocities stay constant for 0.1 seconds as seen in Figure 29 .

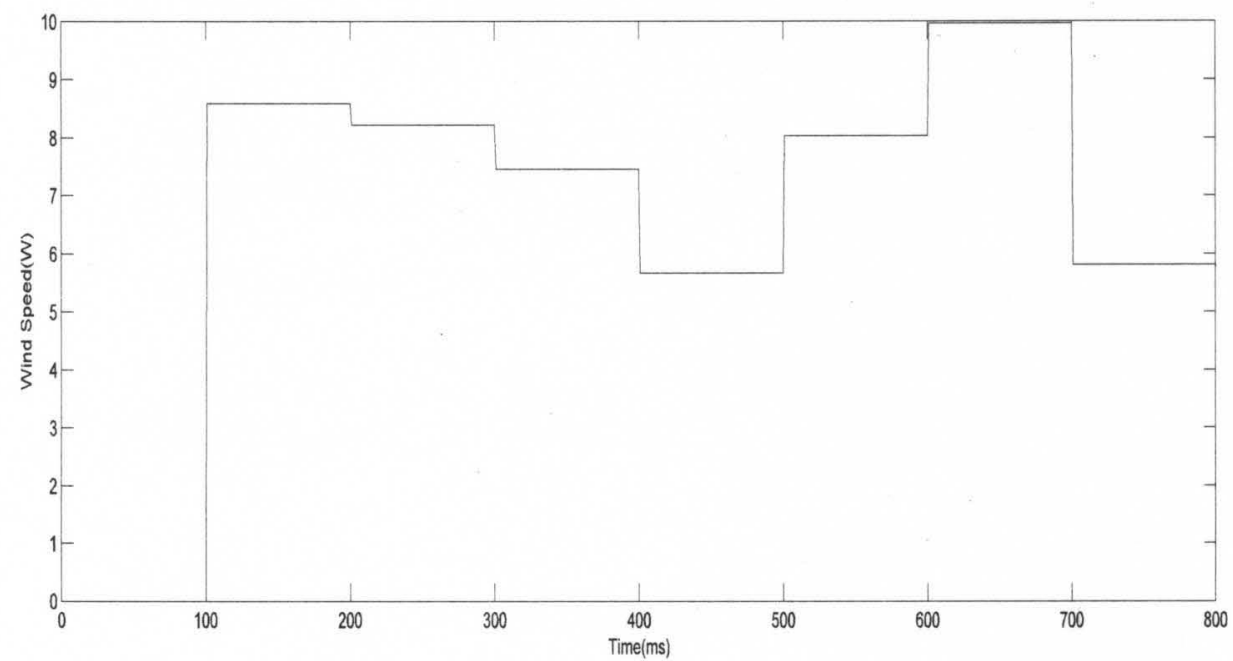

Figure 29. Varying Speed Wind Profile

Figure 30 shows the power extraction from the turbine at various times during the simulation along with the expected values. At all instants, the proposed algorithm has produced more power than HCS with no ripples. The peak efficiency demonstrated by the proposed algorithm was $97.36 \%$, while the HCS method showed a maximum efficiency of $93.95 \%$. 


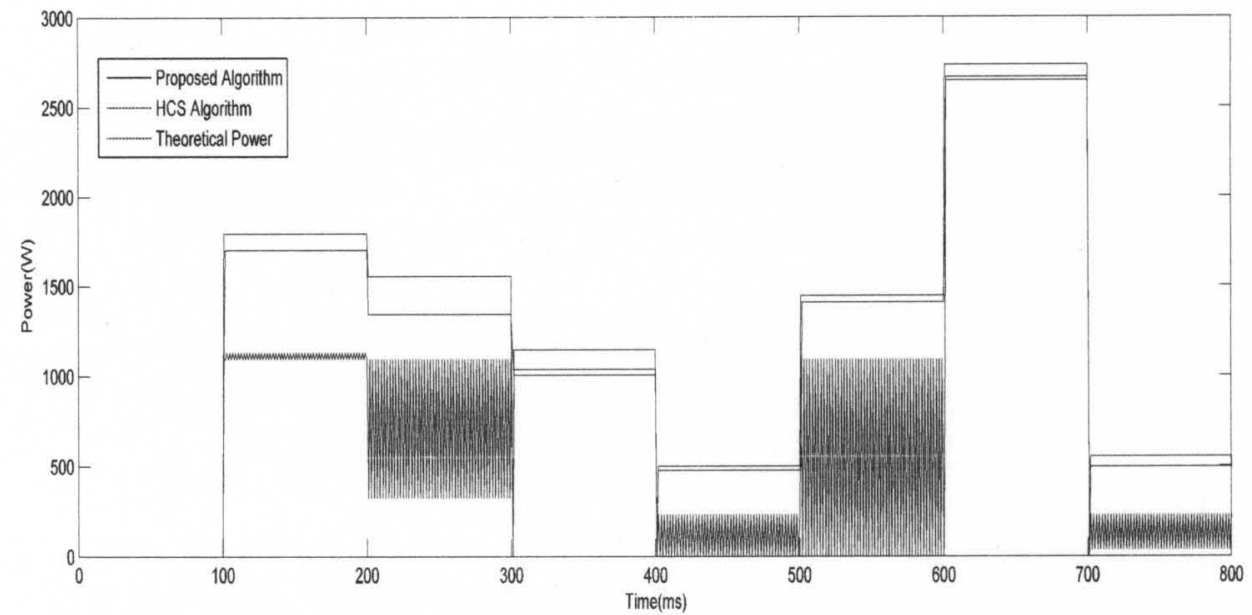

Figure 30. Power produced during constantly varying Wind Conditions

Shown in Figure 31 is the output voltage, which is equal to the expected output voltage of $500 \mathrm{~V}$.

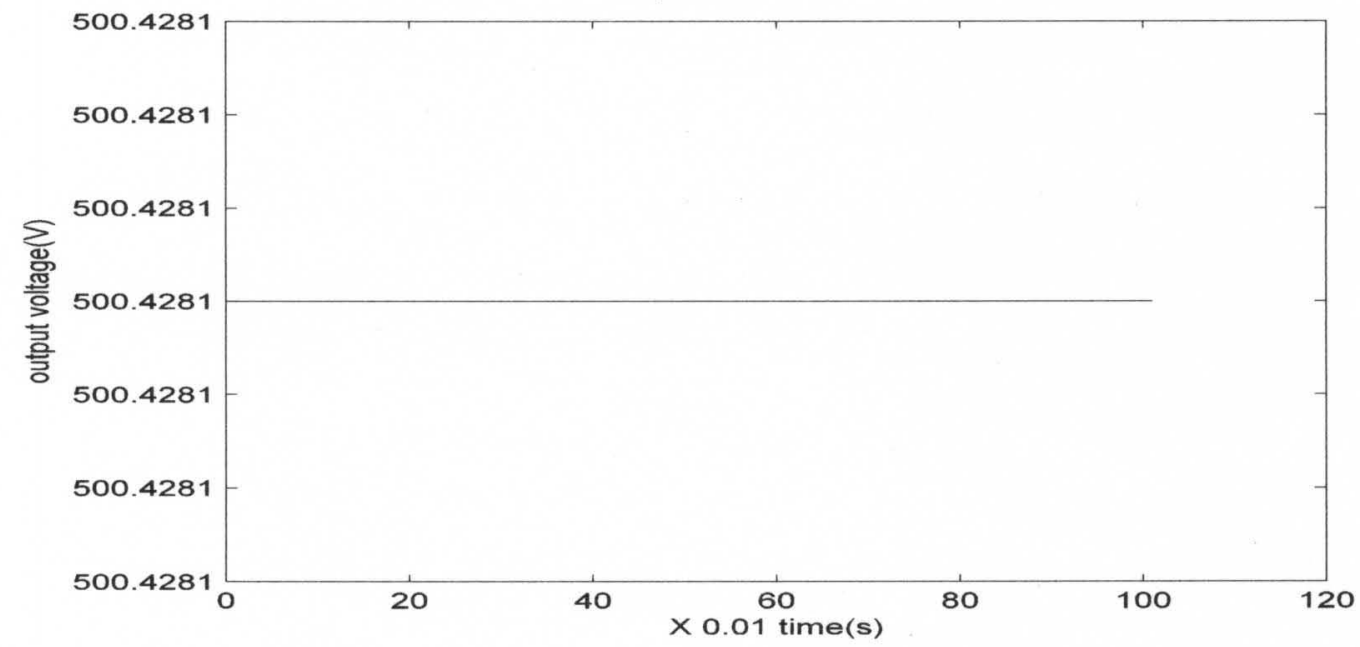

Figure 31. Regulated Output Voltage -Randomly Varying Wind Conditions

At this juncture, a view of the variation of duty cycle over the time is worth viewing as this indicates the efficacy of the algorithm in detecting the peak with minimum oscillations. 


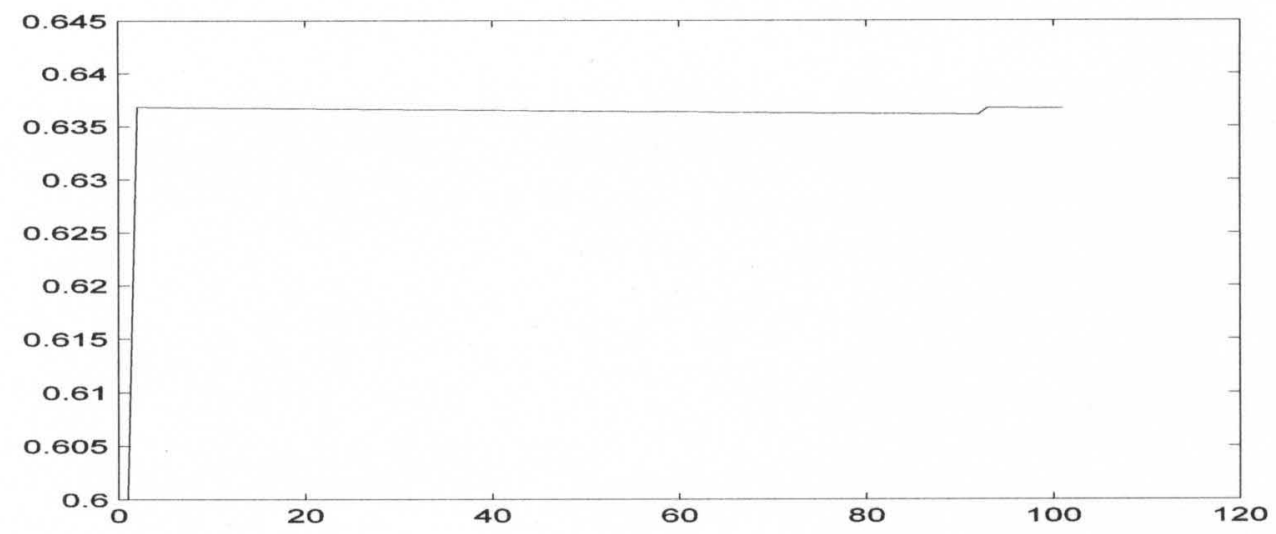

Figure 32. Variation of duty cycle (D) to aid the MPPT.

Figure 32 shows the variation of duty cycle aiding MPPT for a constant wind profile. It can be seen that there are big steps taken when the search has begun. However, as the peak has been detected, the step sizes are small and almost constant making sure that the power produced is also constant with no oscillations.

The results obtained in Section 5.4.3 show that the proposed algorithm performs satisfactorily in case of randomly varying wind speeds, which makes the algorithm appealing in real world applications where the wind speeds are not usually constant.

This chapter presented the proposed algorithm. It also explained the reason for the choice of MATLAB-SIMULINK as simulation environment. It also presented the basic mathematical models used in the thesis to simulate the proposed algorithm. The later part of the chapter describes in detail about the various test conditions set up to examine the validity of the proposed algorithm. 


\begin{tabular}{|c|c|c|c|c|c|c|}
\hline $\begin{array}{c}\text { Simulated } \\
\text { Wind } \\
\text { Profile }\end{array}$ & $\begin{array}{c}\text { Wind } \\
\text { Velocity } \\
(\mathrm{m} / \mathrm{s})\end{array}$ & $\begin{array}{l}\text { Extracted } \\
\text { Power- } \\
\text { Proposed } \\
\text { Algorithm } \\
\text { (W) }\end{array}$ & $\begin{array}{l}\text { Extracted } \\
\text { Power- } \\
\text { HCS } \\
\text { Algorithm } \\
\text { (W) }\end{array}$ & $\begin{array}{c}\text { Expected } \\
\text { Output } \\
\text { Power } \\
\text { (W) }\end{array}$ & $\begin{array}{c}\text { Efficiency } \\
\text {-Proposed } \\
\text { Algorithm } \\
(\%)\end{array}$ & $\begin{array}{c}\text { Efficiency- } \\
\text { HCS } \\
\text { Algorithm } \\
(\%)\end{array}$ \\
\hline Constant & 5 & 328 & 262 & 343.5 & 95.48 & 76.27 \\
\hline \multirow{2}{*}{$\begin{array}{l}\text { Abruptly } \\
\text { Changing } \\
(10 \mathrm{~m} / \mathrm{s}-5 \\
\mathrm{m} / \mathrm{s})\end{array}$} & 10 & 2647 & 2375 & 2750 & 97.6 & 86.36 \\
\hline & 5 & 336.5 & 262 & 343.5 & 97.96 & 76.27 \\
\hline \multirow{3}{*}{$\begin{array}{l}\text { Randomly } \\
\text { Changing } \\
\text { (3 instants } \\
\text { considered) }\end{array}$} & 8 & 1410 & 1113 & 1443 & 97.17 & 77.13 \\
\hline & 5.7 & 500 & 230 & 523.97 & 95.56 & 43.97 \\
\hline & 10 & 2663 & 2643 & 2813.85 & 94.65 & 93.25 \\
\hline
\end{tabular}

It has been proven that the new algorithm detects the peak power with very minimal oscillations in all wind conditions and the algorithm proved to be efficient under rapidly fluctuating wind conditions. 
Taking into account all the simulation profiles, the average efficiency of the proposed algorithm was found to be $95.5 \%$ while for the HCS algorithm; this was found to be 75.16 . This means that the proposed algorithm can extract $20 \mathrm{~W}$ more than the HCS algorithm, for every available $100 \mathrm{~W}$ of power. 


\section{CHAPTER 6}

\section{CONCLUSIONS}

Having simulated the proposed algorithm for different wind conditions, this chapter discusses the achievements realized by this new algorithm. Additionally, some potential issues associated with the algorithm are discussed. Finally, new research directions for the algorithm are presented.

\subsection{MERITS OF THE PROPOSED ALGORITHM}

The simulated MPPT algorithm shows promising results with a number of achievements. In the following section, few of the remarkable achievements made by the algorithm have been described.

\subsubsection{Performance under different kinds of wind behaviors}

The proposed algorithm was tested under different wind conditions including constant wind speed, abruptly changing wind speed, and randomly varying wind speed. In all the scenarios, the power extraction from the turbine was at the peak with respect to the wind curves for the turbine. The reduced ripple in power and increased efficiency are the biggest achievements of the algorithm. No notable ripple was found when the 
proposed algorithm was simulated compared to the HCS method. The turbine efficiency was found to be more than the HCS in all the simulated wind profiles. On an average the proposed algorithm harvested $20 \mathrm{~W}$ more than the HCS per $100 \mathrm{~W}$ of available power with efficiency averaging at $95.5 \%$. The HCS algorithm demonstrated an efficiency of $75.16 \%$.

\subsubsection{Effective decision making capabilities}

Sections 5.4.3 and 5.4.2 validate the decision-making capability of the algorithm in the case of changing wind velocities. It can be seen from Figure 27 and Figure 30 that a change in wind speed has led to the correct direction of perturbation and the peak was detected with good accuracy. This is a big improvement from the conventional HCS method of MPPT.

\subsubsection{Simplicity of HCS maintained}

HCS method of MPPT is appealing because of its inherent simplicity and ease of implementation. Many researchers like Kazmi, Goto, Guo, \& Ichinokura ( 2011), have made HCS efficient, but sacrificed its simplicity. The proposed algorithm, however, has been successful in maintaining the simplicity of HCS, while making it more efficient. No

changes in the hardware such as: usage of an extra memory element (Hui \& Bakhshai, 2009), another sensor, or PID controllers are required; and only a few changes in the software were added. 


\subsubsection{Wind turbine characteristic independency}

A notable feature of the proposed algorithm is that it is highly independent of the wind turbine's characteristics. This is a significant achievement compared to some of the hybrid algorithms mentioned in the literature search. This independency means that the proposed algorithm can be actualized for any wind turbine, and that the tracking efficiency will not be affected by the wear and tear of the turbine. The algorithm was demonstrated to be independent of the wind turbine characteristics by observation that there was no preprograming of any parameters in the simulation of the wind turbine characteristics.

\subsection{SUGGESTED IMPROVEMENTS}

Despite the numerous achievements of the proposed algorithm, there are new directions for any researcher to further improve the algorithm and obtain better performance of WECS.

The thesis discusses the development of the new algorithm using a nonreactive resistive load. In real world applications, the load would be an inverter stage coupled to the grid or a battery load. A simulation that investigated these features is something that could be pursued in future.

The next step after the simulation of the algorithm should be to design a circuit board and program a DSP controller or FPGA chip to validate the real world accuracy of the algorithm. A miniature turbine that receives wind power from a fan could be setup or even the programmed processor can be used along with a real wind turbine that is being field tested. These were initially considered at the start of this work, however, due to the 
limited availability of time, this was not realized. An attempt to implement a hardware setup as stated would help to better reveal the performance of the proposed algorithm in an actual WECS. A hardware implementation is beneficial to study the effects of sensor noise, which requires filtering. Also, the delay for analog to digital conversion could be studied during a hardware implementation. These are factors should be observed as these could slow down the proposed search algorithm.

The mechanical and dynamic characters of turbine and generator were not considered for the project. For example, before implementing the algorithm on a wind turbine, its mechanical characteristics, such as inertia, have to be studied and simulated as these have significant impacts on the performance of the algorithm. In real world applications, the inertia associated with the wind turbine prevents the wind turbine from responding quickly to the wind speed changes, especially when there are wind gusts. This will result in transient behavior of the output power as the peak is being detected.

\subsection{FINAL DISCUSSIONS}

Due to the depletion of non-renewable sources of energy, it is high time that there is more focus on extracting power from renewable sources like wind energy at the maximum possible efficiency. A step towards this end is demonstrated by the thesis. The thesis studied the advantages and drawbacks associated with the various conventional MPPT methods adopted in wind harvesting. After reviewing the available literature, this thesis highlighted the inefficiencies and limitations associated with the HCS method in MPPT employed in WECS traditionally. A promising algorithm eliminating the peak power hunting issues was proposed. This proposed modified HCS algorithm also verified 
that the correct decisions were made in changing the perturbation directions in the case of abruptly changing wind speed profiles. The proposed algorithm detected the wind change by comparing the last two values of tip speed ratio. The proposed algorithm is adaptive with automatically adjusting duty cycle values. This helps to reduce the power variations once the peak has been detected without a compromise in tracking time. Care was given to make the algorithm inexpensive and to maintain the simplicity of HCS. Also, the proposed algorithm is independent of wind turbine characteristics. The effectiveness of the algorithm was verified by simulation using MATLAB-SIMULINK. The simulation was conducted for constant wind, abrupt wind change and also a randomly varying wind profiles. All the simulations showed that the algorithm was efficient in detecting the peak in order of 0.001 seconds and there were no oscillations once the peak was detected. The proposed algorithm achieved an average efficiency of $95.5 \%$, while the HCS algorithm showed on an average efficiency of $75.16 \%$. The thesis also suggests some future research directions that could be done to make the algorithm more efficient and allow real world implementation. Some of these suggestions include: simulation of an inverter and battery load, the study of the mechanical and dynamic characteristics of the components, and implementing the algorithm on an FPGA or DSP controller. In summary, the thesis was able to study the issues faced by employing a traditional HCS method of MPPT and proposed an adaptive solution to overcome these. Simulations of this solution were performed using MATLAB-SIMULINK, which verified improved results in efficiency and operation. 


\section{REFERENCES}

DIY energy projects. (n.d.). Parts-DIY. Retrieved mayx vpturbines, 2011, from VPturbines website: http://www.vpturbines.com/html/tech.html

A Greenpeace Southeast Asia Report. (2005). Bringing Calamiies to communities:Coal fired power plants and mirant.

Adegas, F. D., Alé, J. A., Reis, F. S., Simioni, G. C., \& Tonkoski, R. (2006). MAXIMUM POWER POINT TRACKER FOR SMALL WIND TURBINES INCLUDING HARMONIC MITIGATION. 2006 European Wind Energy Conference \& Exhibition.

Aganah, K., \& Leedy, A. (2011). A constant voltage maximum power point tracking method for solar powered systems. System Theory, IEEE 43rd South Eastern Symposium, (pp. 125130).

allaboutcircuits.com. (n.d.). Retrieved from http://forum.allaboutcircuits.com/showthread.php?t=6963

Amei, K., Takayasu, Y., Ohji, T., \& Sakui, M. (n.d.). A maximum power control of wind generatorsystem using a permenant magnetsynchronus generatorand a boost chopper circuit.

bama.ua.edu. (n.d.). Retrieved from bryan buckly projects: http://bama.ua.edu/ bwbuckley/projects/mppt.html

Betz, A. (1966). Introduction to the Theory of Flow Machines. Oxford: Pergamon Press.

Bharanikumar, R., \& Nirmal Kumar, A. (2010). Analysis of Wind Turbine Driven PM Generator. International Journal of Computer and Electrical Engineering.

Borowy, B., \& Ziyad, S. (1997). Dynamic response of a stand-alone wind energy conversion system with battery energy storage to a wind gust. IEEE transactions on energy conversion, 73-78. 
Caleb Engineering, LLC. (n.d.). Resources: Generator Design. Retrieved May 21, 2011, from Caleb Engineering, LLC website: www.calebengineering.com

Coilgun Systems. (n.d.). electromagnetic pistol voltage converter. Retrieved from coilgun systems website:

http://www.coilgun.eclipse.co.uk/electromagnetic_pistol_voltage_converter_design.ht $\mathrm{ml}$

Congress of the United States Congressional Budget Office. (2006). The Economic Effects of Recent Increases in Energy Prices.

Dang, T. (2010). Introduction, history, and theory of wind power. North American Power Symposium,2009, (pp. 1-6).

Energetic Drives. (n.d.). Retrieved from Energetic drives website:

http://www.energeticdrives.com/website/pages/turbine-lg.html

Femia, N., Petrone, G., Spagnuolo, G., \& Vitelli, M. (2005). Optimization of perturb and observe maximum power point tracking method. Power Electronics, IEEE Transactions, 963-973.

Full Wave Rectifier:Electronics planet blogspot. (n.d.). Retrieved from Electronics planet blogspot: http://electronics-planet.blogspot.com/2011/05/full-wave-rectifier.html

fullwiki.org. (n.d.). Buck Boost Converter:fullwiki. Retrieved from fullwiki.org: http://www.thefullwiki.org/Buck\%E2\%80\%93boost_converter

Green Energy 2011. (n.d.). Retrieved from http://www.greenenergy2011.info/about/windenergy/vertical-axis-wind-turbine

Greenpeace Briefing. (n.d.). Interesting Facts about Coal fired power plants, mercury, and other pollutants.

Hilloowala, R., \& Sharaf, A. (1996). A rule-based fuzzy logic controller for a PWM inverter in a stand alone wind energy conversion scheme ., IEEE Transactions on Industry Applications , 57-65.

hindawi.com. (n.d.). hindawi.com. Retrieved from http://www.hindawi.com/journals/ijp/2010/245316/fig9/

Hua, G., \& Geng, Y. (2006). A Novel Control Strategy of MPPT Taking Dynamics of Wind Turbine into Account. Power Electronics Specialists Conference, 2006., (pp. 1-6).

Hui, J., \& Bakhshai, A. (2009). Adaptive algorithm for fast maximum power point tracking in wind energy systems. Industrial Electronics, 2008. IECON 2008. 34th Annual Conference, (pp. 2119-2124). 
Hussein, K., Muta, I., Hoshino, T., \& Osakada, M. (1995). Maximum photovoltaic power tracking: an algorithm for rapidly changing atmospheric conditions. IEEE transactions on Generation, Transmission and Distribution, 59-64.

Integrated Publishing. (n.d.). Electrical Enigneering Series. Retrieved from tpub.com: http://www.tpub.com/content/neets/14179/css/14179_228.htm

Kazmi, S., Goto, H., Guo, H.-J., \& Ichinokura, O. (2011). A Novel Algorithm for Fast and Efficient Speed-Sensorless Maximum Power Point Tracking in Wind Energy Conversion Systems . IEEE tansactions on Industrial Electronics, 29-36.

Koutroulis, E., \& Kalaitzakis, K. (2006). Design of a maximum power tracking system for windenergy-conversion applications. IEEE transactions on Industrial Electronics, 486 - 494.

Liu, B., Duan, S., Liu, F., \& Xu, P. (2007). Analysis and Improvement of Maximum Power Point Tracking Algorithm Based on Incremental Conductance Method for Photovoltaic Array. Power Electronics and Drive Systems Conference, (pp. 637-641).

Liu, X., \& Lopes, L. (2004). An improved perturbation and observation maximum power point tracking algorithm for PV arrays . Power Electronics Specialists Conference.

mathworks.com. (n.d.). configurable Simulink model for DC-DC Converters. Retrieved from www.mathwork.com:

http://www.mathworks.com/matlabcentral/fx_files/18833/3/content/html/Configurabl eDCConverter.html

Moor, G., \& Beukes, H. (2004). Maximum power point trackers for wind turbines. Power Electronics Specialists Conference, 2004l, (pp. 2044-2049).

Muljadi, E., \& Butterfield, C. (2001). Pitch-Controlled Variable-Speed Wind Turbine Generation. IEEE transactions on Industry Applications, 240-246.

National Instruments. (n.d.). N/ developer Zone-wind turbine control methods. Retrieved from NI developer zone: http://zone.ni.com/devzone/cda/tut/p/id/8189

Powered by mother nature. (n.d.). wind energy:Powered by mother nature. Retrieved from powered by mothernature : http://www.poweredbymothernature.com/wind-energy

Powered by mother nature-renewable energy information center. (n.d.). wind energy:Powered by mother nature. Retrieved from powered by mothernature website: http://www.poweredbymothernature.com/wind-energy

Qaio, W., Harley, R., \& Venayegamoorthy, G. (2007). Dynamic Modeling of Wind Farms with Fixed-Speed Wind Turbine Generators. Power Engineering Society General Meeting, 2007 (pp. 1-8). IEEE. 
Raju, A., Fernandes, B., \& Chatterjee, K. (2011). Modelling and simulation of a Grid connected Variable speed Wind EnergyConversion System with Low Cost Power Converters. Maharashtra, India.

Raza, K., Goto, H., Guo, H.-J., \& Ichinokura, O. (2008). A novel speed-sensorless adaptive hill climbing algorithm for fast and efficient maximum power point tracking of wind energy conversion systems. Sustainable Energy Technologies, 2008. ICSET 2008., (pp. 628-633).

reclaiming the culture.com. (n.d.). Retrieved from http://www.reclaimingtheculture.org/solarenergy/semiconductors.html

reuk. (n.d.). Three Phase Bridge Rectifier: reuk.co.uk. Retrieved from reuk.co.uk: http://www.reuk.co.uk/Three-Phase-Bridge-Rectifier.htm

roads $2 \mathrm{Hy}$. com. (n.d.). Retrieved from http://www.ika.rwthaachen.de/r2h/index.php/Power_Electronics

scielo. (n.d.). STAND-ALONE WIND ENERGY CONVERSION SYSTEM WITH MAXIMUM POWER TRANSFER CONTROL. Retrieved from http://www.scielo.cl/scielo.php?pid=S071833052009000300006\&script=sci_arttext

Serban, I., lon, C., \& Marinescu, C. (2008). Frequency control and unbalances compensation in stand-alone fixed-speed wind turbine systems. Industrial Electronics Conference 2008, (pp. 2167-2172).

Spee, R., Bhowmik, S., \& Enslin, J. (1994). Adaptive control strategies for variable-speed doublyfed wind power generation systems. Industry Applications Society Annual Meeting, 1994., , (pp. 545 - 552 vol.1).

Tafticht, T., Agbossou, K., \& Cheriti, A. (2006). DC bus control of variable speed wind turbine using a buck-boost converter. Power Engineering Society General Meeting, 2006.

Wai, R.-J., \& Lin, C.-Y. (2006). Implementation of Novel Maximum-Power- Extraction Algorithm for PMSG Wind Generation System without Mechanical Sensors. Robotics, Automation and Mechatronics, 2006 IEEE Conference, (pp. 1-6).

Wasynezuk, O. (1985). Dynamic Behavior of a Class of Photovoltaic Power Systems . Power Apparatus and Systems, IEEE transactions, 3031-3037.

Wei, T. C., T.C, G., \& C.A, H.-A. (2009). Analysis of perturb and observe maximum power point tracking algorithm for photovoltaic applications. Power and Energy Conference,2008 (pp. 237-242). IEEE.

what when how.com. (n.d.). Retrieved from http://what-when-how.com/electronics-andmotor-drives/half-bridge-inverter-electronics-and-motor-drives/ 
www.renewable-energy-sources.com. (n.d.). Retrieved from www.renewable-energysources.com: http://www.renewable-energy-sources.com/2010/02/23/depletion-ofnon-renewable-energy-sources-january-2010-status/

Xiao, W., \& Dunford, W. (2004). A modified adaptive hill climbing MPPT method for photovoltaic power systems . Power Electronics Specialists Conference 2004, (pp. 1957-1963).

Xuesong, Z., Daichun, S., Youjie, M., \& Deshu, C. (2010). The simulation and design for MPPT of PV system Based on Incremental Conductance Method. Information Engineering,2010 WASE International, (pp. 314-317).

Yaoqin, J., Zhongqing, Y., \& Binggang, C. (2002). A new maximum power point tracking control scheme for wind generation. Power System Technology, PowerCon, 2002., (pp. 144-148). 


\section{APPENDIX}

The following section shows the codes used to simulate the WECS used in this thesis along with the algorithm. Some of the major blocks used are the wind turbine, PMSG generator, power electronic block and the algorithm block. The wind turbine block checks if the wind velocity is above $4 \mathrm{~m} / \mathrm{s}$ as the power curve has been drawn for velocities above $4 \mathrm{~m} / \mathrm{s}$. It then uses the modeling equations $5.7,5.8,5.10$ mentioned in chapter 5 to give out the power, torque and the angular velocity. The PMSG has been modeled to give the terminal voltage to the rectifier, which has been modeled as said in chapter 5. Also the boost chopper was modeled using equation 5.25. The rectifier and the boost converter together form the power electronic block. The algorithm block follows the above said blocks. The algorithm block is coded so that the block diagram in Figure 20 is implemented perfectly.

\section{WIND TURBINE BLOCK}

if( $(v>4)$

$\mathrm{we}=\mathrm{wg} / 10$ 
$\mathrm{l}=\mathrm{rad}^{*} \mathrm{we} / \mathrm{v}$; Oo telation between TSR, radius of turbine. rotational speed ofof wrbine and the wind velocity where I-TSR, rad-oradius.

$\mathrm{cp}=0.043-(0.108 * 1)+(0.146 * 1 * 1)-(0.0602 * 1 * 1 * 1)+(0.0104 * 1 * 1 * 1 * 1)-(0.0006 * 1 * 1 * 1 * 1 * 1)$

on relation between the TSR and power coeflicient cp.

$\mathrm{p}=\left(0.5^{*} 3.14 * \operatorname{den} *\left(\operatorname{rad}^{\wedge} 5\right) *\left(\mathrm{we}^{\wedge} 3\right) * \mathrm{cp}\right) /\left(1^{\wedge} 3\right)$

QPover genetated by the turbine where $p$ is the power. den is the air density

tor $=0.5 * 3.14 * 1.5 * 1.5 * 1.5 * \mathrm{v} * \mathrm{v} * \mathrm{cp} / 1$

Da Torque generated by the turbine blales where tor is the oforqua

tk=tor/5;

if $(v>15)$

$\mathrm{p}=0 ; \%$ if the wind velocity was outside the values in the wind

$\mathrm{tk}=0$;

$\mathrm{cp}=0$

we $=0$

$1=0$;

endif 
end

end

\section{GENERATOR BLOCK}

$w g=(1-d) * 684$

Urelation beiween the generator velocity and the output

ovoltage $d=$ duty cycle and value of 684 is got by

substituting the value of generator logd resistance

$R v=\left((3.14)^{2}-18\right),(1-d)^{2} R=500$ ohms

$\mathrm{E}=0.314 * w g$

Wo voltage at the output of generator is denoted as L? oand

00,314 is the generator ratio.

$\mathrm{ig}=\mathrm{p} /\left(3^{*} \mathrm{E}\right)$

$\mathrm{pg}=\mathrm{E} * \mathrm{ig}$

$\%$ current at the output of the generator

Oo power generated at the generator output

end

\section{POWER ELECTRONICS}

$\mathrm{vdc}=2.33^{*} \mathrm{vg}$

\% DC bus voltage Vdo as a function of generator terminal

\section{voltage}

idc=ig*1.28;

$\%$ DC current as a function of the generator outpuf current

$\mathrm{po}=\mathrm{vdc} * \mathrm{idc}$

QDCC Power

$\mathrm{vo}=\mathrm{vdc} /(1-$ duty $)$;

OnOutput voliage regulated using a dc-dc comverter

end 


\section{ALGORITHM BLOCK}

$\mathrm{si}=\mathrm{sg}$

duty=duty1;

$\mathrm{ak}=\mathrm{ak} 1$

$\mathrm{sg} 1=\mathrm{sg}$

if $(\mathrm{v}-\mathrm{vo}<0.5)$

$\operatorname{if}((p>30) \&(p>p o) \& \&(p-p o)<30)$

Q checking if the perturbation point is near peak

$\mathrm{ak}=\mathrm{ak} 1 * 0.25$

Whif so reduce incrementing factor by $25 \%$

duty $=$ duty $1+$ duty $1 * 0.01 * \mathrm{ak}^{*} \mathrm{si}$

of change in duty cycle

$\mathrm{sg} 1=\mathrm{si}$;

Oo moving the new value of sign to old value variable

elseif ( $p>$ po)

or cheching if it was in LHS of the curve but not near peak

duty $=$ duty $1+0.1 *$ si;

Oo fixed increment as in MCS method

$\operatorname{sg} 1=\mathrm{si}$;

$\mathrm{ak}=\mathrm{ak} 1$

elseif $((\mathrm{p}<\mathrm{po}) \&(\mathrm{p}-\mathrm{po})>(-30))$

o checks if the perturbation point is just past the peak point

$\mathrm{ak}=\mathrm{ak} 1 * 0.25$ 


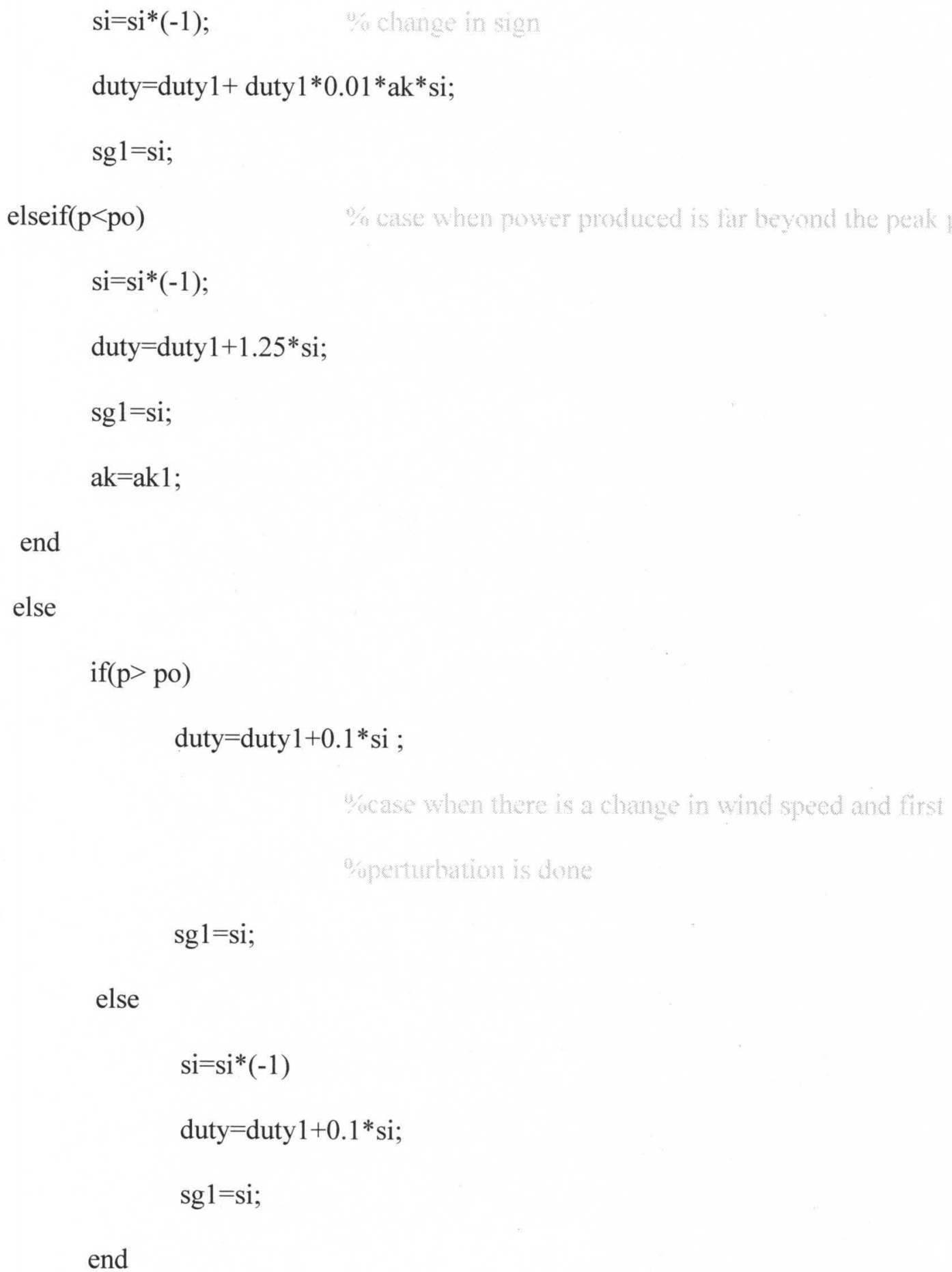




\section{CURRICULUM VITAE}

NAME : : George Joseph

ADDRESS

: $\quad$ 784, Raymond Kent Ct

Louisville,Ky-40217

DOB

: $\quad$ Thrissur, Kerala, India - August 16, 1988

EDUCATION $\quad: \quad$ BTECH-University of Calicut,Kerala,India 